\title{
Replication-selective oncolytic viruses in the treatment of cancer
}

\author{
Bart Everts, ${ }^{1}$ and Henk G van der Poel $^{2}$ \\ ${ }^{1}$ Department of Biomedical sciences, University of Amsterdam, Kruislaan 318, 1098 SM, Amsterdam, \\ The Netherlands; and ${ }^{2}$ Department of Urology, Netherlands Cancer Institute, Plesmanlaan 121, 1066 CX, \\ Amsterdam, The Netherlands.
}

\begin{abstract}
In the search for novel strategies, oncolytic virotherapy has recently emerged as a viable approach to specifically kill tumor cells. Unlike conventional gene therapy, it uses replication competent viruses that are able to spread through tumor tissue by virtue of viral replication and concomitant cell lysis. Recent advances in molecular biology have allowed the design of several genetically modified viruses, such as adenovirus and herpes simplex virus that specifically replicate in, and kill tumor cells. On the other hand, viruses with intrinsic oncolytic capacity are also being evaluated for therapeutic purposes. In this review, an overview is given of the general mechanisms and genetic modifications by which these viruses achieve tumor cell-specific replication and antitumor efficacy. However, although generally the oncolytic efficacy of these approaches has been demonstrated in preclinical studies the therapeutic efficacy in clinical trails is still not optimal. Therefore, strategies are evaluated that could further enhance the oncolytic potential of conditionally replicating viruses. In this respect, the use of tumor-selective viruses in conjunction with other standard therapies seems most promising. However, still several hurdles regarding clinical limitations and safety issues should be overcome before this mode of therapy can become of clinical relevance.
\end{abstract}

Cancer Gene Therapy (2005) 12, 141-161. doi:10.1038/sj.cgt.7700771

Published online 8 October 2004

Keywords: oncolysis; tumors; replication competent virus; clinical trials

$\mathrm{C}$ ancer has become one of the leading causes of death in the Western society. As current cancer therapies, like radiotherapy and chemotherapy, have often only a limited effect, a strong need exists for novel approaches to the treatment of cancer. One of these approaches is the use of viruses.

Gene therapy seeks to treat cancer by the introduction of genes that will either kill cells by sensitizing them to other therapies, or by enhancing an immune response against transfected cells. Most of gene therapy strategies to date utilize replication defective viruses, because of the risk of uncontrolled viral spread when replication competent virus are given to patients. If, however, one's goal is to eliminate the transfected cells, as is the case in cancer, then one may take advantage of the inherent cytotoxic characteristics viral replication exhibits. The heavy biochemical demands that the virus makes upon its host cell in order to replicate, will often lead to apoptotic cell death. ${ }^{1}$ In addition, upon completion of the virus replication cycle, many viruses induce lysis of the host cell, allowing further spread of the newly synthesized virus particles to other cells. ${ }^{2}$ Since some viruses can directly damage and kill cells, one may exploit these pathogens to mediate cell lysis of specific cell populations, like tumors.

Received April 26, 2004.

Address correspondence and reprint requests to: Dr Henk G van der Poel, Department of Urology, Netherlands Cancer Institute, Plesmanlaan 121, 1066 CX, Amsterdam, The Netherlands.

E-mail:h.vd.poel@nki.nl
This idea of using replication competent viruses in the battle against cancer instead of using replication defective ones, has led to the rise of a novel mode of cancer therapy: oncolytic virotherapy.

In the beginning of this century, it was noticed that a patient with cervical carcinoma experienced significant tumor regression after rabies vaccination. ${ }^{3}$ In addition, there are reports of remissions of Burkitt's and Hodgkin's lymphomas following natural infection with measles virus. $^{4,5}$ In the $1950 \mathrm{~s}$, human trials with several potentially oncolytic viruses were initiated. ${ }^{6-11}$ Although tumor regression was reported in some cases, these studies generally demonstrated lack of significant antitumor efficacy of this mode of therapy. As a result, this mode of therapy was abandoned for almost two decades. Advances in our understanding of the basic principles of viral biology, including cell cycle control and carcinogenesis, and the discovery of recombinant DNA technology in the intervening years have resulted in the current revival of oncolytic viruses as a cancer therapy. Following the first description of a virus engineered to replicate selectively in dividing cells a decade ago, ${ }^{12}$ the field of oncolytic virotherapy has significantly expanded. Results from preclinical studies with several virus types have been quite promising, and several different virus species have entered or even completed clinical trials (Table 6).

Currently, a wide variety of virus types is under study that can be roughly divided into two groups. On the one hand, there are inherently oncolytic wild-type strains. On the other hand, several virus types are rendered 
tumor-selective by genetic modifications. This paper will focus on the biological principles underlying tumorselective replication of these viruses and strategies by which their oncolytic potency can be improved, with particular emphasis on the use of these viruses in multimodal antitumor regimens. In addition, an outline will be given of the current status of the field concerning viruses studied both in preclinical settings and in clinical trials. Lastly, the potential limitations and safety issues will be discussed that will, for a large part, determine whether oncolytic viral therapy can become a standard cancer therapy in the future.

\section{Mechanisms of tumor-selective replication}

\section{Naturally occurring oncotropic viruses}

Since the cellular changes induced by viral infection are often strikingly similar to cellular changes acquired during carcinogenesis (for example, inactivation of p53, inhibition of apoptosis, and induction of mitosis), it is not surprising that given this genetic convergence many viruses preferentially grow in tumor cells. Several of these naturally occurring oncotropic viruses are used for oncolytic virotherapy (Table 1).

Reovirus. This virus is a nonenveloped double-stranded RNA virus with minimal pathogenicity in humans. ${ }^{2}$ Although its preferential tropism and cytotoxicity for neoplastic cell lines has been acknowledged for a long time, ${ }^{13}$ the underlying mechanism had not been elucidated until recently. Mouse fibroblasts, which are normally resistant to reovirus infection, become susceptible to infection following transformation by activation of the ras-pathway, which is often constitutively activated in tumors. ${ }^{14,15}$ In addition, Strong et $\mathrm{al}^{16}$ demonstrated that deletion of the gene coding for double-stranded RNA- activated protein kinase (PKR), which is a key component of the intracellular host defense system against pathogens like viruses, allows reovirus infection and replication. These findings implicate that reovirus, as it is not able to directly block the antiviral effects of PKR, as some other viruses do (see below), depends on activated ras-pathways in order to circumvent the effect of PKR (see Figure 1).

Given the fact that approximately half of the tumors bear an activating mutation in the ras-pathway, ${ }^{17}$ reovirus might be an ideal oncolytic agent. Reovirus has been shown to destroy selectively many different types of neoplastic cells, including those derived from breast, colon, ovaries, and lymphoid malignancies both in vitro and in xenograft mice models both intratumoral (i.t.) ${ }^{14,18-21}$ and intravenously (i.v.). ${ }^{18}$ However, in these preclinical studies, immunodeficient mice were used, in which the oncolytic effect of the virus is not affected by possible antiviral immune responses. Reovirus treatment combined with immune suppression (cyclosporine A or anti-CD4/anti-CD8 antibodies) further enhanced the oncolytic effects. $^{22}$ Altogether, these results will likely inspire further investigation into the potential use of reovirus as an anticancer agent.

Newcastle disease virus $(N D V)$. This virus is an enveloped chicken paramyxovirus that carries its genetic information on a negative single-stranded RNA molecule. The virus is not pathogenic to humans and it was first reported to have oncolytic activity in the mid-1950s. ${ }^{23}$ There are indications that NDV similar to reovirus is dependent on an activated ras-pathway to be able to replicate efficiently. ${ }^{24}$ Defects in the IFN-pathway, which are often found in tumor cells, might also render these cells NDV sensitive.

A strain of NDV, 73-T, so named because it was passaged 73 times through mouse ascites cells in vitro has

Table 1 Natural tumor selective viruses

\begin{tabular}{|c|c|c|c|c|}
\hline Virus & Class, Subclass & $\begin{array}{l}\text { Genetic/phenotypic target } \\
\text { within tumors }\end{array}$ & Advantage & Disadvantage \\
\hline NDV & ssRNA $^{-}$, rhabdovirus & $\begin{array}{l}\text { Activated ras-pathway; } \\
\text { defective IFN-pathway }\end{array}$ & $\begin{array}{l}\text { Infects primarily tumor cells } \\
\text { Not pathogenic in humans } \\
\text { Antigenicity generates immune } \\
\text { reponse } \\
\text { Does not establish permanent } \\
\text { infection in host }\end{array}$ & $\begin{array}{l}\text { Transgene insertion reduces viral } \\
\text { replication }\end{array}$ \\
\hline Reovirus & dsRNA, reovirus & Activated ras-pathway & $\begin{array}{l}\text { Mild pathogenicity } \\
\text { Unable to infect normal cells } \\
\text { Antigenicity generates immune } \\
\text { reponse }\end{array}$ & $\begin{array}{l}\text { Infects only cells with activated } \\
\text { ras-pathway }\end{array}$ \\
\hline $\begin{array}{l}\text { Autonomous } \\
\text { parvovirus }\end{array}$ & ssDNA, parvovirus & IFN-resistance of tumors & $\begin{array}{l}\text { Unable to infect nondividing cells } \\
\text { No pathogenicity }\end{array}$ & $\begin{array}{l}\text { Not very effective in inducing cell } \\
\text { lysis }\end{array}$ \\
\hline VSV & ssRNA $^{-}$, rhabdovirus & Loss of cell cycle control? & $\begin{array}{l}\text { Unable to infect normal cells } \\
\text { Very high replication rates }\end{array}$ & $\begin{array}{l}\text { Infects only cells with defective } \\
\text { IFN-pathway } \\
\text { Very high replication rates }\end{array}$ \\
\hline
\end{tabular}

NDV, Newcastle disease virus; VSV, vesicular stomatitis virus; IFN, interferon; ds, double stranded; ss, single stranded; ssRNA ${ }^{-}$, RNA as a template for mRNA. 


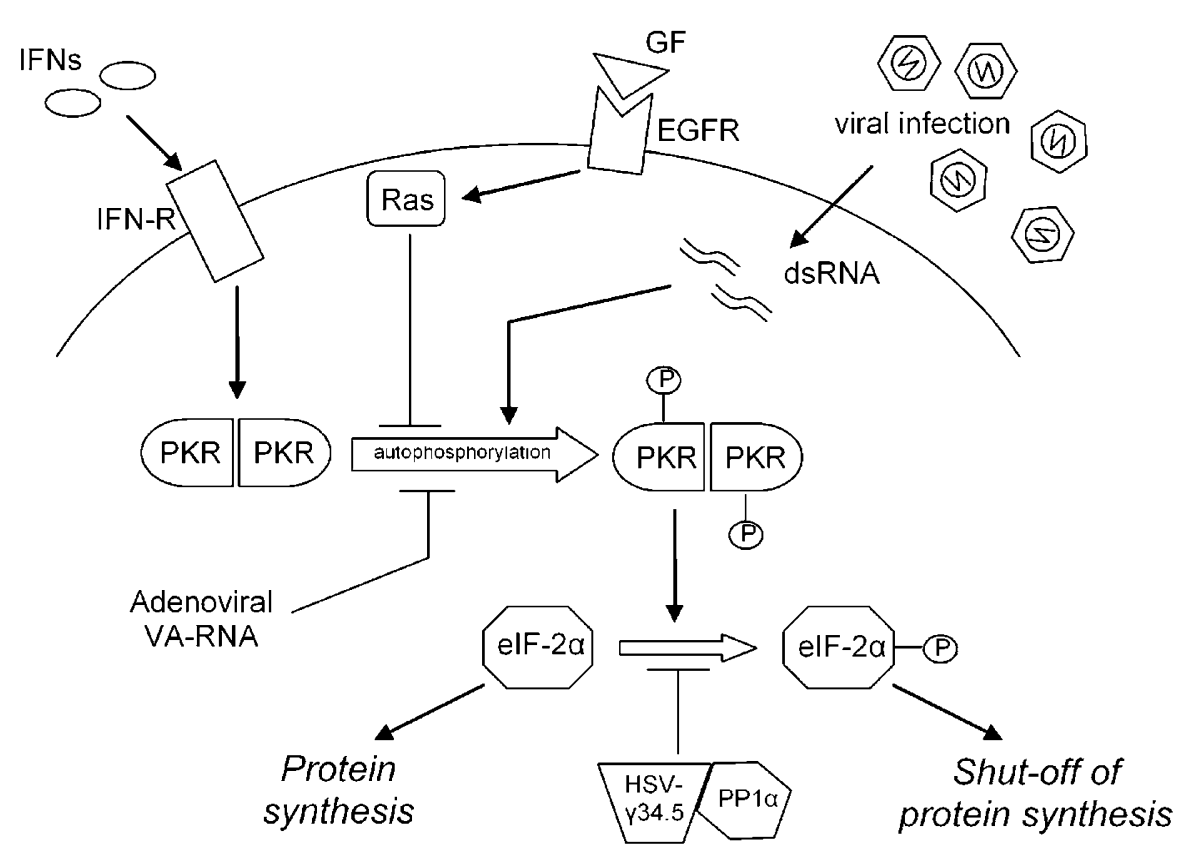

Figure 1 Role of PKR in viral infection. PKR is an important downstream effector molecule of the interferon (IFN) signalling pathway. The IFN signalling system is part of the host defense system against pathogens like viruses. When a cell is infected by a virus, it is stimulated to produce IFNs that will activate an antiviral defense response of nearby cells. Upon binding of IFNs to cell surface receptors (IFN-Rs) on neighboring cells, an intercellular signal transduction cascade is engaged, that induces PKR expression. When PKR, subsequently, encounters viral doublestranded (ds) RNA, PKR will bind to the RNA. This event leads to autophosphorylation of the PKR homodimer and activation of its kinase activity. Activated PKR phosphorylates elF-2 $\alpha$, which in turn inhibits protein synthesis and thereby viral replication. However, in tumor cells this pathway is often deregulated. For example, in many tumor cells inactivating mutations of the IFN signalling pathway can be found (VSV is dependent on this characteristic for its natural oncotropism). In addition, a constitutively activated ras signal transduction pathway, which is a commonly found feature in tumor cells, leads to inhibition of PKR autophosphorylation (for example reovirus is dependent on this characteristic for its natural oncotropism). On the other hand, viruses have also developed mechanisms themselves to inhibit this antiviral response. Adenovirus can produce so-called virus-associated (VA) RNAs that bind to PKR leading to inactivation of it. Furthermore, herpesvirus is able to express the protein $\gamma 34.5$. By interacting with cellular phosphatase $1 \alpha(\mathrm{PP} 1 \alpha), \gamma 34.5$ dephosphorylates elF-2 $\alpha$ and induces host protein synthesis needed for viral replication (GF $=$ growth factor, EGFR $=$ epidermal growth factor receptor).

been shown to induce significant tumor regression in several different tumor lines and mouse models bearing fibrosarcoma, neuroblastoma, colon, prostate, large cell lung or breast carcinoma xenografts. ${ }^{24,25}$ Apart from its use as a direct oncolytic virus, it has also been studied as part of a viral oncolysate, which is a suspension of virus and tumor cells, as a mode for cancer therapy. ${ }^{26}$

Another naturally attenuated strain of NDV, designated PV701, also exhibits a high potency and tumor selectivity against a broad range of human tumors as $80 \%$ of human cancer cell lines are two to four log orders more sensitive than normal cells to PV701-mediated killing. Furthermore i.t. treatment of several human tumor xenografts caused high rates of tumor regression in a mouse model (reviewed by Mullen and Tanabe ${ }^{27}$ ). The encouraging results have led to the initiation of a phase I trial of i.v. administration of PV701 in patients with advanced solid cancers. Little toxicity was reported even at high doses, and two partial responses occurred at high dose levels. ${ }^{28}$ Additional clinical studies are now underway.

Vesicular stomatitis virus (VSV). This virus is an enveloped negative single-stranded RNA rhabdovirus and is primarily of veterinary importance. However, the virus has been shown to replicate more efficiently in transformed cell lines relative to nontransformed cell lines. ${ }^{29}$

VSV is known to be exquisitely sensitive to IFNmediated antiviral effects and is dependent on cells that have a malfunctioning IFN-pathway to make replication possible. ${ }^{29}$ Mutations causing defects in the IFN-pathway are often found in tumor cells, because apart from its antiviral effects (Fig 1), the IFN-mediated signal cascade can also lead to growth inhibitory and apoptotic signals. As a result, these tumor cells with mutated IFN-pathways may have a growth and/or survival advantage, but are at the same time more susceptible to viral infections like VSV.

In vivo work showed that in athymic mouse models i.t. injection of VSV was effective in reducing the tumor size of subcutaneous human melanoma xenografts. ${ }^{29}$ Treatment of VSV in an immune-competent mouse model of metastatic colon cancer, resulted in complete and durable cures in the majority of treated animals. ${ }^{30}$ Furthermore, the survival of multifocal hepatocellular carcinoma was significantly prolonged after administration into the hepatic artery. ${ }^{31}$ Although these results are encouraging, further research is needed to find out whether VSV can be 
used as an oncolytic tool for the treatment of interferon nonresponsive tumors.

Autonomous parvovirus. This virus is a small nonenveloped single-stranded DNA virus. Unlike other DNA viruses, it is unable to force resting cells into $\mathrm{S}$ phase and is therefore incapable of undergoing genome replication in quiescent cells. Therefore, the efficiency with which parvoviruses replicate in transformed cell lines relative to nontransformed cell lines is probably due to the aberrant cell cycle control exhibited by transformed cells (reviewed by Rommelaere and Carnelis ${ }^{32}$ ). Although autonomous parvovirus has proven to have antineoplastic activity in vitro, ${ }^{33}$ it is often not potent enough to kill all tumor cells equally well. ${ }^{32,34,35}$ Delivery of cytotoxic compounds to tumor cells by parvoviral vectors, was demonstrated to enhance the intrinsic antitumor effect of autonomous parvovirus in human tumor cell cultures. ${ }^{36,37}$ Results from in vivo studies will determine whether there is a possible application of recombinant autonomous parvoviruses as a therapy for some human cancers.

\section{Engineered tumor-selective viruses}

Viruses are also being evaluated that are genetically engineered for tumor selectivity. The main approach by which viruses can be made tumor selective is by modification of the cellular tropism at the level of viral replication in a way that it becomes dependent on specific characteristics of tumor cells for viral replication. This can either be achieved by deleting viral genes that are critical for viral replication in healthy cells but are dispensable upon infection of neoplastic cells (Table 2), or, on the other hand, by placement of tumor-specific promoters upstream of viral genes that are critical for efficient viral replication (Table 3). Modification of the cellular tropism at the level of cell recognition and binding has also been performed by altering the viral coat for tumor-selective binding and uptake. However, this strategy has mainly been applied to replication deficient viruses and for that it falls beyond the scope of this review and we would like to refer to other papers. ${ }^{38-40}$

\section{Viral gene deletion mutants}

Adenovirus gene deletion mutants. One of the most extensively studied viruses that has been genetically engineered for oncolytic purposes is adenovirus, in particular serotypes 2 and 5. It is a nonenveloped, linear, double-stranded DNA virus with a genome size of approximately $38 \mathrm{~kb}$. It is endemic in the human population and its natural pathogenicity is associated only with mild respiratory infections. In order to replicate, adenoviruses promote entry into the cell cycle of the host cell through expression of the E1A and E1B. E1A competes with E2F for binding to $\mathrm{pRb}$, resulting in release of transcription factor E2F and subsequent transition from $\mathrm{G} 1$ into $\mathrm{S}$ phase. In addition,

Table 2 Examples of viral gene deletions to achieve tumor-selective replication

\begin{tabular}{|c|c|c|c|c|c|}
\hline $\begin{array}{l}\text { Parental } \\
\text { strain }\end{array}$ & Agent & Genetic alteration & Genetic/phenotypic target within tumours & $\begin{array}{l}\text { In clinical } \\
\text { trials }\end{array}$ & References \\
\hline \multirow[t]{5}{*}{ Adenovirus } & ONYX-015 & E1B-55kd deletion & $\begin{array}{l}\text { p53 null/mutant or/and inactivated p53- } \\
\text { pathway }\end{array}$ & I-III & 41 \\
\hline & Ad- $\Delta 24$ & E1A CR2 deletion & $\begin{array}{l}\mathrm{pRb} \text { null/mutant or/and loss of cell cycle } \\
\text { control }\end{array}$ & No & 60 \\
\hline & $\mathrm{CB}-1$ & E1A CR2 deletion; E1B-55kd deletion & $\begin{array}{l}\mathrm{pRb} \text { and p53 defective pathways or/and } \\
\text { loss of cell cycle control }\end{array}$ & No & 61 \\
\hline & $d / 922-947$ & E1A CR2 deletion & $\begin{array}{l}\mathrm{pRb} \text { null/mutant or/and loss of cell cycle } \\
\text { control }\end{array}$ & No & 59 \\
\hline & $d / 331$ & VA-1 gene deletion & Ras-activated pathway & No & 62 \\
\hline \multirow{5}{*}{$\begin{array}{l}\text { Herpes } \\
\text { simplex } \\
\text { virus-1 }\end{array}$} & dlsptk & Thymidine kinase gene deletion & Replication & No & 12 \\
\hline & R3616 & Deletion of both $\gamma 34.5$ genes & Loss of neurovirulence & No & 65 \\
\hline & $\mathrm{HrR3}$ & ICP6 gene deletion & Replication & No & 67 \\
\hline & G207 & $\begin{array}{l}\text { Deletion of both } \gamma 34.5 \text { genes; } \\
\text { ribonucleotide reductase disruption }\end{array}$ & Replication; loss of neurovirulence & $1-I 1$ & 69 \\
\hline & NV1020 & $\begin{array}{l}\text { Deletion of one } \gamma 34.5 \text { gene; deletion in tk } \\
\text { gene; insertion of exogenous copy of tk } \\
\text { gene }\end{array}$ & Replication, loss of neurovirulence & I & 72 \\
\hline \multirow{3}{*}{$\begin{array}{l}\text { Vaccinia } \\
\text { virus }\end{array}$} & VV-TK ${ }^{-}$ & Thymidine kinase gene deletion & Replication & No & 75 \\
\hline & VV-SPI-1/2- & Deletion of SPI-1 and SPI-2 genes & Replication & No & 27 \\
\hline & WDD & $\begin{array}{l}\text { Thymidine kinase gene deletion; deletion } \\
\text { of VGF gene }\end{array}$ & Replication & No & 76 \\
\hline Polio virus & PV1(RIPO) & $\begin{array}{l}\text { IRES element replaced by IRES from } \\
\text { HRV2 }\end{array}$ & Loss of neurovirulence; replication & No & 77 \\
\hline $\begin{array}{l}\text { Influenza } \\
\text { virus }\end{array}$ & IVA-NS1 ${ }^{-}$ & NS1 gene deletion & IFN-pathway deficiency & No & 78 \\
\hline
\end{tabular}

tk, thymidine kinase; IRES, internal ribosomal entry site; HRV2, human rhinovirus type 2; IFN, interferon. 
Table 3 Examples of tissue- and tumor-specific promoters used for tumor-selective replication of oncolytic viruses

\begin{tabular}{|c|c|c|c|}
\hline Promoter & Tissue/tumour type & Applied virus & References \\
\hline Osteocalcin promoter & Osteosarcoma & Adenovirus & 82 \\
\hline PSA promoter & Prostate & Adenovirus & 79,81 \\
\hline AFP promoter & Hepatocellular carcinoma & Adenovirus & 84,85 \\
\hline Tyrosinase promoter & Melanocytes & Adenovirus & 87 \\
\hline \multirow[t]{2}{*}{ MUC-1 promoter } & \multirow[t]{2}{*}{ Breast carcinomas } & Adenovirus & 86 \\
\hline & & HSV-1 & 102 \\
\hline Midkine differentiation factor promoter & Neuroblastoma & Adenovirus & 90 \\
\hline Rat probasin promoter & Prostate & Adenovirus & 81 \\
\hline Leukoprotease inhibitor promoter & Ovarian carcinoma & Adenovirus & 89 \\
\hline \multirow[t]{2}{*}{ Tcf responsive promoter } & \multirow{2}{*}{ Colon cancer } & Adenovirus & 91 \\
\hline & & Autonomous parvovirus & 103 \\
\hline Calponin promoter & Smooth muscle cells & HSV-1 & 101 \\
\hline Albumin enhancer/promoter & Liver & HSV-1 & 99 \\
\hline Flt-1 promoter & Teratocarcinoma & Adenovirus & 96 \\
\hline E2F-1 promoter & Cancer cells in general & Adenovirus & 93 \\
\hline Telomerase reverse transcriptase promoter & Cancer cells in general & Adenovirus & 94,95 \\
\hline Hypoxia responsive elements & Cancer cells in general & Adenovirus & 97 \\
\hline
\end{tabular}

PSA, prostate-specific antigen; AFP, $\alpha$-fetoprotein; Flt-1, vascular endothelial growth factor receptor type 1; HSV-1, herpes simplex virus-1.

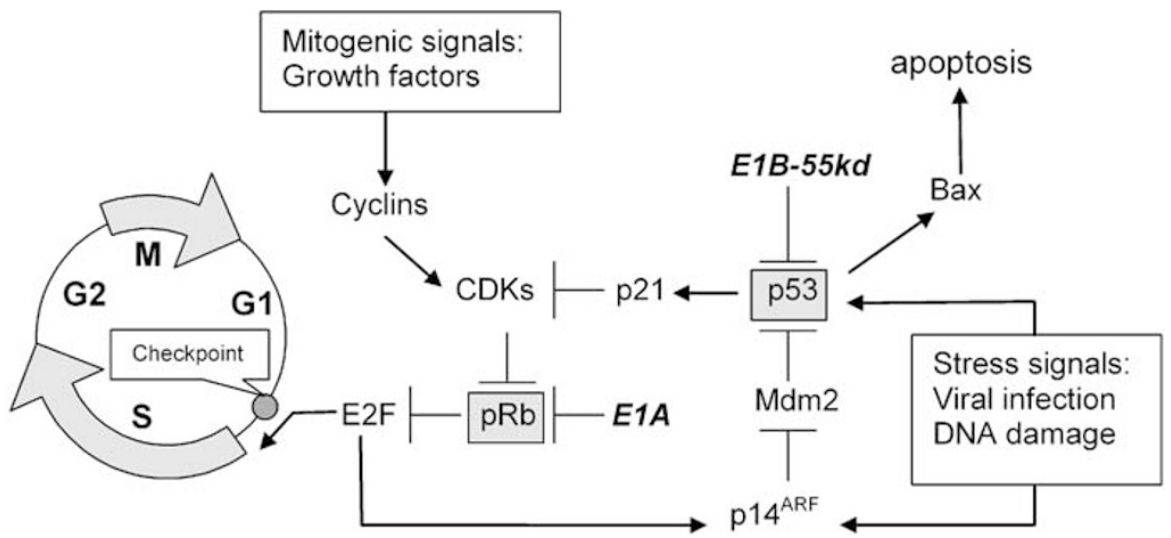

Figure 2 Cell cycle control mechanisms. The retinoblastoma protein family (pRb) regulate the G1 to S-phase cell cycle checkpoint. When pRb is hypophosphorylated it prevents progression of the cell cycle from $\mathrm{G} 1$ to $\mathrm{S}$ phase. $\mathrm{pRb}$ exerts this effect by binding to and repressing transcription factor E2F, which normally induces expression of genes needed for DNA synthesis. When a cell receives a mitogenic signal, one of the upregulated proteins is cyclin $\mathrm{D}$, which subsequently enables cyclin-dependent kinase 4 (CDK4) to phosphorylate pRb. As a result of this phosphorylation, $\mathrm{pRb}$ is not able to bind to and repress E2F anymore, leading to progression into the $\mathrm{S}$ phase and subsequent cell cycle phases. Another protein that is of great importance with regard to cell cycle control is tumor suppressor protein p53. p53 is a transcription factor that is upregulated and activated upon stress signals like DNA damage or viral infection. p53 can activate transcription of genes coding for proteins that either induce apoptosis (for example Bax) or cell cycle arrest (for example p21). p21 is able to inactivate CDKs, thereby inhibiting progression through the cell cycle. The activity of p53 is counteracted by Mdm2, that inactivates p53 through binding and subsequent ubiquitin mediated degradation. In its turn, the effect of Mdm2 can be inhibited by $\mathrm{p} 14^{\mathrm{ARF}}$, a tumor suppressor protein that is upregulated by stress signals and mitogenic signals, like E2F. As E2F activity is blocked by pRb, inactivation of pRb leads to activation of p53 and functions as a safety mechanism during progression through the cell cycle. Altogether, it is not surprising that inactivation of the critical pRB or p53 pathways by either mutations (as in tumors) or intervention by viral proteins, like adenoviral E1A and E1B-55kd, will lead to loss of cell cycle control (reviewed by Sherr ${ }^{162}$ ).

E1B-55kd is able to bind and inactivate p53. If it were not for E1B-55kd expression, cellular levels of p53 would rise in response to adenoviral infection with resulting apoptosis or cell cycle arrest attenuating viral replication (Fig 2). Nearly all tumors possess defects in their p53 and/or pRb pathways. Thus, E1A and $\mathrm{E} 1 \mathrm{~B}$ gene products become dispensable in these tumor cells, as E1A- or E1B-defective adenoviruses can still replicate in $\mathrm{pRb}$ - or p53-defective tumor cells, respectively. In contrast, replication of these mutated viruses is attenuated in normal cells with intact p53 en $\mathrm{pRb}$ pathways.

The first conditionally replicative adenovirus (also termed CRAd), ONYX-015 (also called $d l 1520$ or CI-1042) 
was reported in $1996 .{ }^{41}$ ONYX-015 is a type 2, type 5 chimeric adenovirus that contains alterations in the E1B gene, resulting in the complete abrogation of E1B-55kd expression. It was demonstrated that ONYX-015 efficiently replicated only in cells lacking functional p53 and it caused significant tumor regression in mice bearing human tumor xenografts, due to tumor-specific viral replication. ${ }^{41,42}$ In spite of this enthusiasm, there have been reports contradicting the mechanism of ONYX-015 selectivity, based on findings that cells with functional p53 also support its viral replication. ${ }^{43-45}$ Several hypotheses have been put forward to explain this apparent contradiction. First, p53 function can be abrogated in tumors by mechanisms other than p53 gene mutations. Loss of function of $\mathrm{p} 14^{\mathrm{ARF}}$, which normally indirectly stabilizes $\mathrm{p} 53$, can result in inactivation of p53 (Fig 2). Ries et al ${ }^{46}$ showed that loss of $\mathrm{p} 14^{\mathrm{ARF}}$ in tumor cells expressing functional p53 facilitates replication of ONYX-015. Second, adenoviral protein E4orf6, which is still present in ONYX-015, is known to bind and inactivate p53 as well and may in part compensate for E1B-55kd loss. ${ }^{47}$ The exact role of p53 status in ONYX-015 infection remains to be elucidated.

The safety and antitumor efficacy of ONYX-015 have been tested in numerous phase I and II clinical trials with multiple tumor types and several routes of administration (for example, intratumoral, intravenous, intra-arterial, and intraperitoneal). In all cases, safety was demonstrated even at doses up to $2 \times 10^{12}$ particles, with most common associated toxicity being flu-like symptoms. Viral replication was tumor selective after administration by all routes, but the local tumor regression was modest, $0-14 \%$ (reviewed by $\mathrm{Kirn}^{48}$ ). The most encouraging results were gained from phase I and II studies using i.t. administration of ONYX-015 in patients with advanced head and neck squamous cell carcinoma. ${ }^{49-51}$ Treatment was well tolerated at the highest dose level $\left(10^{11} \mathrm{PFU}\right)$ and the virus was shown to replicate in tumor cells but not in peritumoral tissue. ${ }^{51}$ Hyperfractionated treatment resulted in $10 \%$ complete response, $62 \%$ stable disease, and $29 \%$ progressive disease rates. Importantly, the presence of high neutralizing antibody titers, which is normal during adenoviral infection, did not prevent infection and/or replication within tumors. ${ }^{49,50}$ However, other clinical trials were less promising. With i.t. treatment of pancreatic tumors or ovarian carcinoma no objective tumor responses were observed. ${ }^{52,53}$ Phase I/II studies in patients with unresectable primary and secondary liver tumors ${ }^{54}$ and colorectal carcinoma liver metastases, ${ }^{55,56}$ showed that intra-arterial administration of ONYX-015 was well tolerated, but did not result in significant tumor regression. On the other hand, intravenous treatment with ONYX-015 did appear least promising, with no evidence of antitumor activity in patients with advanced carcinoma metastatic to the lung ${ }^{57}$ and stable disease in some patients with metastatic colorectal cancer but only for a few months. ${ }^{58}$ Although ONYX-015 seems not to be very successful in most cancers as monotherapy, it does hold promise in combination with other therapies like chemotherapy, radiation therapy and gene therapy (see 'Oncolytic Virotherapy in a multimodal antitumor approach' section).

Another strategy that has been used to make adenoviruses tumor selective is by mutation of the E1A gene. E1A mutant adenovirus, dl922-947, with a small deletion in conserved region $2(\mathrm{CR}-2)$ of E1A was shown to replicate specifically in cancer cells with abnormalities in the $\mathrm{pRb}$-pathway and to reduce the incidence of metastases in a breast tumor xenograft model following intravenous injection. ${ }^{59}$ Another E1A mutant, termed $\Delta 24$, carrying a 24-bp deletion in CR-2 responsible for $\mathrm{pRb}$ binding, displayed efficient replication in $\mathrm{pRb}$ lacking cells, while infection of cells with functional $\mathrm{pRb}$ was strongly attenuated. ${ }^{60}$ In vivo, multiple injections induced $83.8 \%$ inhibition of tumor growth in nude mice.

These E1A virus mutants have not yet been tested in clinical trials, but are more promising as antitumor agent than ONYX-015, since dl922-947 demonstrated significantly greater potency compared to ONYX-015 both in vitro and in vivo. ${ }^{59}$ The reduced potency of ONYX-015 might be due to the loss of p53-independent E1B-55kd functions. E1B-55kd also plays a role in viral mRNA transport. ${ }^{45}$ Abolishment of this function as well, is likely to reduce viral replication efficacy. In contrast, the E1A deletions of $d l 922-947$ and $\Delta 24$ only abolish its binding capacity to bind $\mathrm{pRb}$, leaving other functions of the E1A gene in tact. In a recent study a novel adenovirus mutant (CB1) harboring targeted deletions in both E1 genes was successfully tested for its oncolytic properties as it induced a potent antiglioma effect both in vitro and in vivo. ${ }^{61}$

Yet, a recent study used another mechanism to make adenovirus tumor selective. Adenovirus produces socalled virus-associated (VA) RNAs that bind to PKR and inactivate it. Viruses (for example reovirus) that are unable to counteract the effect of PKR, replicate to higher levels when PKR is inhibited by activated ras-pathways. Since activated ras-pathways are often found in tumors, adenovirus mutants that are unable to produce VA RNAs can be rendered tumor selective (Fig 1). Cascallo et al ${ }^{62}$ demonstrated ras-dependency of a VA RNA mutant for replication and might be of use in therapy of tumors with constitutively activated ras-pathways, like pancreatic tumors.

HSV-1 gene deletion mutants. Besides adenovirus, herpes simplex virus 1 is one of the most extensively studied viruses for oncolytic virotherapy. HSV-1 is an enveloped, double-stranded DNA virus with a genome size of approximately $152 \mathrm{~kb}$ and is generally neurotropic. It rarely produces severe medical illness in immunocompetent adults. It is an attractive virus for gene therapy, since as much as $30 \mathrm{~kb}$ of its genome may be replaced for delivery of transgenes.

The utility of gene deletion mutants was first demonstrated with HSV in $1991 .{ }^{12}$ In this mutant, termed $d$ lsptk, the thymidine kinase gene (HSV-tk) was deleted, which is normally needed for nucleic acid metabolism. For its replication, this mutant is dependent on endogenous levels of this enzyme, which is only found in high concentrations in replicating cells. Accordingly, $d l$ sptk 
replicated selectively in glioma cell lines and i.t. administration caused growth inhibition of U87 human glioma in both nude ${ }^{12}$ and immunocompetent mice. ${ }^{63}$ However, apart from infection of tumor cells, healthy neurons were also infected and neurotoxicity was found. ${ }^{64}$ In addition, these mutants are resistant to antiviral agents acyclovir and ganciclovir by virtue of their disrupted HSV-tk gene. For safety reasons, sensitivity to agents that can block unwanted replication is desirable. Therefore, investigators have come up with other HSV-1 mutants that are still sensitive to antiherpetics and show less neurovirulence.

One such mutated virus harbors mutations in both $\gamma 34.5$ loci $^{65}$ (Fig 3). The protein product of $\gamma 34.5$ blocks the shut-off of host protein synthesis in infected cells by interacting with cellular phosphatase $1 \alpha(\mathrm{PP} 1 \alpha)$ to dephosphorylate eIF-2 $\alpha$. This leads to production of more progeny viruses from each infected cell (Fig 1). Due to specific deletions in this gene, these HSV mutants are strongly attenuated for their replication in normal cells, like neurons, leading to loss of their neurovirulence. ${ }^{65,66}$ However, $\gamma 34.5$ mutated HSV-1 replicated in actively dividing cells, like tumor cells. Moreover, these mutants were still sensitive to antiherpetics, as the HSV-tk locus is not disrupted. Yet, another genetically engineered virus has been produced, that contains mutations in the ICP6 gene, normally encoding the large subunit of ribonucleotide reductase, needed for generation of deoxyribonucleotides for DNA synthesis ${ }^{67}$ (Fig 3). ICP6-mutated viruses replicate only in actively dividing cells that provide ribonucleotide reductase in complementation, rendering them tumor selective. Drug sensitivity assays showed that this ICP6 mutant virus was hypersensitive to ganciclovir and showed significant inhibition of tumor growth after i.t. administration in mice bearing human glioblastoma tumors $^{67}$ or colon carcinoma. ${ }^{68}$

More recently, herpes viruses have been engineered that contain mutations in more than one gene. The major advantage of this multiple mutation approach relative to single gene mutations is the reduction of chance of reversion to wild-type strains, so providing an extra level of safety. A promising HSV-1 mutant is G207, ${ }^{69}$ which has deletions in both ã34.5 loci and an inactivating insertion in the ICP6 gene (Fig 3). G207 is not neurovirulent and is sensitive to antiherpetics. Furthermore, G207 exhibits tumor cell-specific replication and antitumor efficacy in both in vitro and in vivo models of malignant gliomas, ${ }^{69}$ colorectal cancers, ovarian cancer, breast cancer and prostate cancer (reviewed by Varghese and Rabkin ${ }^{70}$ ). A phase I clinical dose escalation study of G207 in the treatment of recurrent malignant glioma was initiated and no toxicity was found, even at the highest doses $\left(3 \times 10^{9} \mathrm{PFU}\right)$. $^{71}$ Unfortunately, no viral replication data are available, but preparations for phase II trials are underway. NV1020 is another genetically engineered oncolytic herpes virus that contains a deletion in the endogenous HSV-tk gene as well a deletion in one of the two $\gamma 34.5$ genes (Fig 3). The NV1020 genome, however, does harbor an exogenous copy of the HSV-tk gene derived from HSV-2. Because of this insertion, NV1020 maintains its sensitivity to acyclovir and ganciclovir. NV1020 was first designed as a candidate for human immunisation against infections with HSV-1 and HSV$2 .^{72}$ After NV1020 was demonstrated to be a safe virus in extensive rodents and primate studies, it was tested for its oncolytic potency in preclinical models of pancreatic carcinoma, transitional cell carcinoma, head and neck squamous cell carcinoma, hormone resistant prostate
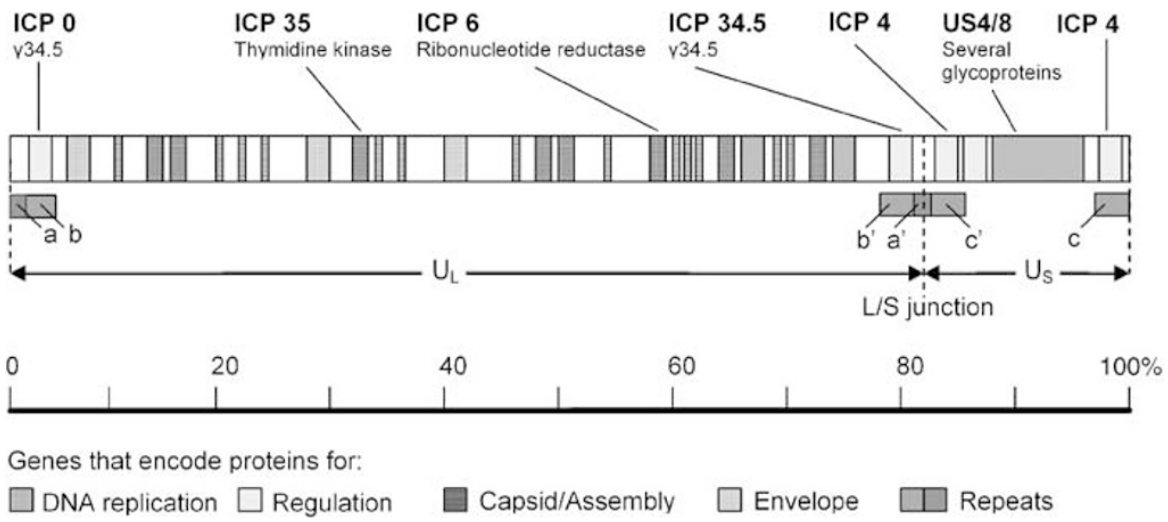

Figure 3 Map of the genome of herpes simplex virus. The HSV-1 genome is a single, linear molecule of double-stranded DNA approximately $152,000 \mathrm{bp}$ in length. It is divided into two unique segments called long $\left(U_{\mathrm{L}}\right)$ and short $\left(\mathrm{U}_{\mathrm{S}}\right)$. Short regions of repeated sequence $\left(\mathrm{a} / \mathrm{b} / \mathrm{c}\right.$ and $\mathrm{a}^{\prime} / \mathrm{b}^{\prime} /$ $c^{\prime}$ ) occur at the genome ends and between the $L$ and $S$ segments. As DNA is replicated, the $L$ and $S$ segments invert at a high rate creating a total of four genome isomers. The four occur at equal frequencies in most wild-type HSV-1 populations. The genome encodes 74 proteins. Most genes encoding proteins are located in the $\mathrm{L}$ or $\mathrm{S}$ regions, and they are named according to their location within $\mathrm{L}$ or $\mathrm{S}$. For example, the US6 gene encodes glycoprotein D, a membrane glycoprotein involved in virus entry, and UL30 encodes the virus DNA-dependent DNA polymerase. HSV1 -encoded proteins can be divided into four main categories based on their function: proteins for (1) virus DNA replication and recombination; (2) transcriptional regulation of HSV-1 gene expression and modulation of the host cell; (3) capsid formation and assembly; and (4) proteins that are embedded in the envelope. A schematic representation of the positions of the genes encoding these proteins in the HSV-1 genome is depicted above. Genes that are modified or deleted to achieve tumor-specific targeting and replication are indicated as well. 
carcinoma, and epidermoid carcinoma (reviewed by Varghese and Rabkin $^{70}$ ). In these studies NV1020 replicated selectively in tumor cells in high titers and caused rapid tumor regression. Comparison of NV1020 with G207 revealed that NV1020 is capable of more efficient viral replication than $\mathrm{G} 207$ in vitro $^{73}$ and that the oncolytic efficacy of NV1020 was superior to G207 at lower concentrations of the virus both in vitro and in vivo. ${ }^{74}$ Given these quite promising results, a phase I trial of intrahepatic arterial injection of NV1020 in patients with colorectal carcinoma liver metastases was recently initiated. Despite the promising results obtained with engineered HSV-1 vectors described thus far, it is likely that multimodal approach to eradication of cancer will be more effective (see the later section).

Vaccinia virus gene deletion mutants. A virus that has just recently come into the picture as an agent for oncolytic virotherapy is vaccinia virus. Vaccinia virus is an enveloped, double-stranded virus with a genome of approximately $200 \mathrm{~kb}$. This large genome size makes it a promising vector as it allows insertion of large genes for virotherapeutic approaches. It is best known as the first widely used vaccine, which resulted in the eradication of smallpox. As a result, its toxicity is well characterized. Until recently, the use of vaccinia virus as an anticancer agent has primarily focused on the induction of an antitumoral immune response, since it is highly immunogenic (see 'Eliciting an antitumor immune response' section). However, recently, investigators have generated vaccinia virus mutants that are replication-conditional such that they destroy cancer cells as a by-product of viral replication in a way that they become oncolytic. The most commonly employed strategy is analogous to the one used in HSV-1 mutants: inactivation of the thymidine kinase (tk) gene. Puhlmann et $\mathrm{al}^{75}$ showed that tk-deficient, replication competent vaccinia virus mutants are selectively oncotropic with several logs higher replication kinetics in tumor cells relative to normal cells. To enhance the tumor specificity of this vector, a combined tk- and vaccinia growth factor-deleted vaccinia virus was developed. $^{76}$ This mutant vaccinia virus was significantly attenuated in resting cells in vitro and demonstrated significant tumor regression after systemic administration with $1 \times 10^{9} \mathrm{PFU}$ in nude mice bearing murine colon adenocarcinoma. Furthermore, a mutant vaccinia virus with improved tumor selectivity has been generated by the deletion of SPI-1 and SPI-2 genes. These viral genes encode serine protease inhibitors that are homologous to proteins known to be upregulated in cancer and so are dispensable upon infection of tumor cells but are required for successful viral replication in normal cells (reviewed by Mullen and Tanabe ${ }^{27}$ ). Most of these mutant vaccinia viruses have been developed for enhanced targeting of therapeutic genes to tumors (see Table 4). Apart from its role in anticancer virotherapy as an efficient gene delivery vector, these studies also raise the possibility of the use of vaccinia virus as direct oncolytic agent in the fight against cancer.
Poliovirus gene deletion mutants. A recent study reported an attenuated poliovirus as a potential antitumoral agent. ${ }^{77}$ Poliovirus is a nonenveloped positive-singlestranded RNA virus, causing the neurodegenerative disease polio, which is now due to the development of an effective vaccine almost completely under control. Translation of the viral noncapped RNA is dependent on a cell type-specific internal ribosomal entry site (IRES) element. Exchange of poliovirus IRES with its counterpart from human rhinovirus type 2 resulted in attenuation of neurovirulence in primates. Despite deficient virus propagation in cells of neuronal origin, nonpathogenic polio recombinants retained excellent growth characteristics in cell lines derived from glial neoplasms and demonstrated strong oncolytic potential against experimentally induced gliomas in athymic mice. These observations suggest that highly attenuated poliovirus recombinants may have antineoplastic effects. Unlike the other viruses described above, this virus contains genetic material derived form two different virus types. The in vivo characteristics, like host cell range and pathogenicity, might therefore have been significantly altered. Thus, it will be of great importance to carefully address these safety issues, before any other studies concerning its clinical relevance can be undertaken.

Influenza virus gene deletion mutants. Recently, a recombinant influenza A virus, normally causing common cold, has been engineered, that lacks the NS1 protein. Since the NS1 protein of influenza virus is a virulence factor that counteracts IFN-mediated antiviral response by the host, this modified virus is dependent on cells with defective IFN pathways, which is often the case in tumors, for efficient replication. The oncolytic potency of NS1-modified influenza virus was demonstrated both in IFN-resistant tumor cells and in a SCID mouse model of a subcutaneously implanted human IFN-resistant melanoma. $^{78}$

\section{Viral dependency on tissue/tumor-specific promoters}

Tissue/tumor-specific promoters constructed into adenovirus. A number of oncolytic adenoviruses have been generated in which expression the early genes E1A, E1B, E3 or/and E4 are under control of exogenous promoters that are preferentially active in tumor cells (see Table 3).

Most research concerning the application of tissuespecific promoters for tumor-specific adenoviral replication has been carried out on prostate cancer. One virus that has been yielded from this line of investigation is CV706. In this CRAd the prostate-specific antigen (PSA) gene promoter-enhancer element is inserted upstream of the E1A gene, which is needed to induce the host cell to enter the cell cycle, thereby allowing viral replication to ensue. PSA is a widely used marker for the diagnosis and management of prostate cancer. Replication kinetics of CV706 were highest in PSA-producing tissues and CV706 was able to destroy large PSA-expressing tumors in an i.t. xenograft mouse model. ${ }^{79}$ In addition, Deweese et $\mathrm{al}^{80}$ demonstrated in a phase I trial that intraprostatic delivery 
of CV706 was safe at high doses and treatment resulted in strong reduction of serum PSA levels. Another prostatespecific oncolytic adenovirus, termed CV787, contains the prostate-specific rat probasin promoter driving E1A expression and the human PSA gene promoter-enhancer element driving the E1B gene. This virus, unlike CV706, contains a wild-type E3 region, which encodes proteins that play a role in viral progeny release and cell lysis (see also Table 4). The presence of a functional E3 region significantly improved cell killing and oncolytic efficacy. ${ }^{81}$ CV787 was shown to destroy PSA $^{+}$cancer cells $10^{4}$ times more efficiently than PSA $^{-}$cells. In SCID mice carrying $\mathrm{PSA}^{+}$tumor xenografts, a single i.v. injection of CV787 eliminated tumors within 4 weeks. ${ }^{81}$ CV787 is currently being studied in clinical trials and results concerning viral safety are underway. Prostate cancer has a high propensity to metastasize to bone, and often resists hormone, radiation, and chemotherapies. Therefore, Matsubara et $\mathrm{al}^{82}$ used the osteocalcin promoter to target adenovirus to metastasized prostate cancer cells. In SCID mice, intraosseous growth of PSA-producing xenografts responded markedly to i.v. administrations of a single dose of the virus. In all, $100 \%$ of the treated mice responded to this systemic therapy with a decline of serum PSA to an undetectable level. These promising results have led to the initiation of clinical trials and are now underway. ${ }^{83}$

In addition to prostate cancer-specific adenoviruses, a range of oncolytic adenoviruses have been engineered that target other tumors based on construction of tissuespecific promoters upstream of E1A. Several studies have reported construction of an adenovirus whose $\mathrm{E} 1 \mathrm{~A}$ is expressed under control of the tumor-specific $\alpha$-fetoprotein (AFP) promoter. AFP is highly expressed in up to $80 \%$ of patients with hepatocellular carcinoma but not in normal adults. Specific replication and lysis was observed in AFP-expressing cell lines, while replication in $\mathrm{AFP}^{-}$ cells was strongly attenuated. ${ }^{84,85}$

Similar strategies were used to target adenoviruses to breast carcinomas, using the DF3/MUC1 gene promoter; ${ }^{86}$ to melanoma cells, using a human tyrosinase enhancer/promoter; ${ }^{87,88}$ ovarian carcinoma, using a secretory leukoprotease inhibitor promoter; ${ }^{89}$ neuroblastoma, using the midkine differentiation factor promoter, ${ }^{90}$ and colon cancer, using a Tcf responsive promoter. ${ }^{91}$ In colon cancer cell lines, it was demonstrated that tumorselective viral replication was further enhanced when multiple early genes (E1A E1B, E2 and/or E4) were under regulation of Tcf-responsive elements. ${ }^{91,92}$

Although viruses harboring tissue-specific promoters have been shown to preferentially replicate in tumor cells, they are limited in that they are only targeted to specific subsets of tumor types. In addition, as these promoters are tissue specific and therefore not necessarily only active in tumors, this approach might lead to some degree of viral replication in tissues other than tumors alone. To overcome this limitation, the use of promoters that are

Table 4 Strategies to improve the intrinsic anti-tumor potency of oncolytic viruses

\begin{tabular}{|c|c|c|c|c|c|}
\hline \multicolumn{2}{|c|}{ Strategy } & \multirow{3}{*}{$\begin{array}{l}\text { Example } \\
\text { Expression of adenoviral E3 } \\
\text { gene coding for adenoviral } \\
\text { death protein } \\
\text { Expression of syncytium- } \\
\text { inducing genes }\end{array}$} & \multirow{2}{*}{$\begin{array}{l}\text { Way of action } \\
\text { Increase of viral-induced cell } \\
\text { lysis }\end{array}$} & \multirow{2}{*}{$\begin{array}{l}\begin{array}{l}\text { Applied virus } \\
\text { (inserted gene) }\end{array} \\
\text { Adenovirus (E3) }\end{array}$} & \multirow{2}{*}{$\begin{array}{c}\text { References } \\
81,105\end{array}$} \\
\hline 1. & $\begin{array}{l}\text { Insertion of genes } \\
\text { encoding cytotoxic } \\
\text { proteins }\end{array}$ & & & & \\
\hline & & & $\begin{array}{l}\text { Increase of cell killing of both } \\
\text { infected and uninfected cells } \\
\text { through syncytium induction }\end{array}$ & Adenovirus (FMG) & 109 \\
\hline & & & & HSV-1 (FMG) & 110 \\
\hline & & $\begin{array}{l}\text { Deletion of apoptosis inhibitor } \\
\text { E1B-19kd protein }\end{array}$ & $\begin{array}{l}\text { More efficient cell killing by } \\
\text { viral-induced apoptosis }\end{array}$ & Adenovirus $(-)$ & 106,108 \\
\hline \multirow[t]{11}{*}{2.} & $\begin{array}{l}\text { Elicitation of an } \\
\text { antitumor immune }\end{array}$ & Expression of cytokine genes & $\begin{array}{l}\text { Activation and stimulation of } \\
\text { tumor-specific cytotoxic } T \text { cells }\end{array}$ & HSV-1 (IL-4) & 120 \\
\hline & & & & HSV-1 (IL-12) & $119,121,163$ \\
\hline & & & & Vaccinia virus (GM-CSF) & 122 \\
\hline & & & & Vaccinia virus (IL-2) & 123 \\
\hline & & & & Parvovirus (MCP-1) & 37 \\
\hline & & & & Adenovirus (IFN) & 118 \\
\hline & & $\begin{array}{l}\text { Use of oncolysates: treatment } \\
\text { with virus-augmented tumor } \\
\text { cells }\end{array}$ & $\begin{array}{l}\text { Elicitation of an immune } \\
\text { response directed against } \\
\text { tumor-specific antigens }\end{array}$ & Vaccinia virus $(-)$ & 113 \\
\hline & & & & VSV (-) & 115 \\
\hline & & & & NDV (-) & 114 \\
\hline & & $\begin{array}{l}\text { Expression of tumor-specific } \\
\text { antigens }\end{array}$ & $\begin{array}{l}\text { Elicitation of an immune } \\
\text { response directed against } \\
\text { tumor-specific antigens }\end{array}$ & Vaccinia virus (CEA) & 117 \\
\hline & & & & Vaccinia virus (PSA) & 116 \\
\hline
\end{tabular}

HSV-1, herpes simplex virus-1; NDV, newcastle disease virus; VSV, vesicular stomatitis virus; GM-CSF, granulocyte-macrophage colony-stimulating factor; MCP-1, monocyte chemotactic protein 1; FMG, fusogenic membrane glycoprotein; IL, interleukin; IFN, interferon; CEA, carcinoembryonic antigen; PSA, prostate-specific antigen. 
specifically active in tumors has been explored. All tumor cells exhibit uncontrolled cell growth due to a deregulated cell cycle generally characterized constitutively active E2F (Fig 2). Based on this observation, an adenovirus has been engineered that contains a human E2F-1 promoter element driving E1A expression. It selectively induced cell lysis of tumor cells while normal noncycling cells were unharmed and showed potent antitumor effects in an ovarian cancer xenograft mouse model. ${ }^{93}$

The telomerase promoter has also been explored as means to direct viral replication to tumor cells. Telomeres become shorter during each cell cycle, limiting the number of cell divisions. The enzyme telomerase is able to lengthen these telomeres, and its expression is a common characteristic of most solid tumors. A CRAd has been developed, which contains a promoter element of human telomerase reverse transcriptase driving E1A expression. Selective cytolysis of telomerase-positive cells was observed and administration of the viral mutant to tumor xenografts resulted in significant inhibition of tumor growth. ${ }^{94,95}$

Growth factor receptors are also often upregulated in tumor cells. One study showed that an adenovirus mutant, containing the E1 gene under control of a vascular endothelial growth factor receptor (flt-1) promoter, was specifically targeted to teratocarcinoma cell lines. ${ }^{96}$ Another option currently being evaluated is the use of hypoxia responsive elements (HREs), as hypoxia is a common hallmark of solid tumors. Hypoxia-inducible factors (HIFs) mediate transcriptional responses to hypoxia by binding to these HREs in target genes. HYPR-Ad\#1, containing an HIF-responsive HRE in the promoter of E1A, caused conditional cytolysis of hypoxic/HIF activated but not normoxic cells. ${ }^{97}$

Several second-generation CRAds have been developed that combine transcriptional targeting with viral gene mutations in order to further restrict viral replication to tumor cells. For example, Nettelbeck et al ${ }^{87}$ have engineered a melanoma targeted CRAd, $\operatorname{AdTyr} \Delta 24$, in which the human tyrosinase enhancer/promoter is used to drive expression of E1A genes containing mutations that abrogate binding to proteins of the $\mathrm{pRb}$ family. Likewise, a viral mutant harboring the promoter of surfactant protein B upstream of E4 coupled with small attenuating deletions in the E1A gene has been demonstrated to specifically replicate in alveolar and bronchial tumor cells. $^{98}$

Tissue/tumor-specific promoters constructed into HSV1. This strategy of using tissue or tumor-specific promoters to target oncolytic viruses to tumor cells has also been applied on HSV-1 vectors. G92A is one such vector, in which an albumin enhancer/promoter - ICP4 transgene is inserted into the thymidine kinase gene of HSV-1 mutant d120, deleted for both copies of the ICP4 gene $^{99}$ (Fig 3). In adults, albumin is exclusively expressed in the liver, and it was shown that G92A replicated 1000 times more efficiently in hepatoma cells than in other nonalbumin-expressing cells. In vivo, G92A replicated well in subcutaneous xenografts of human hepatoma cells in athymic mice, but not in nonhepatoma subcutaneous tumors. I.t. inoculation of G92A inhibited the growth of established subcutaneous hepatoma tumors in nude mice, but not prostate tumors. ${ }^{100}$ Another HSV-1 mutant has been engineered, using the calponin promoter to drive expression of ICP4 to target viral replication. ${ }^{101}$ Normally, calponin is expressed in maturated smooth muscle cells, but is aberrantly expressed in a variety of malignant soft tissue and bone tumors. In cell culture, the virus selectively killed calponin-positive human synovial sarcoma, leiomyosarcoma, and osteosarcoma cells. Furthermore, in a leiomyosarcoma xenograft nude mouse model i.t. viral treatment resulted in total tumor regression in four out of five mice. More recently, it was demonstrated that insertion of the $\mathrm{DF} 3 / \mathrm{MUC} 1$ promoter/enhancer sequence in front of the $\gamma 34.5$ locus resulted in effective eradication of $\mathrm{DF} 3 / \mathrm{MUCl}^{+}$carcinoma xenografts in nude mice. ${ }^{102}$

Tissue/tumor-specific promoters constructed into autonomous parvovirus. More recently, a study reported the use of transcriptional targeting in redirecting autonomous parvoviral replication to colon cancer cells. In most colon tumors the wnt-signalling pathway is constitutively activated due to mutations in the adenomatous polyposis coli and $\beta$-catenin genes, leading to expression of genes involved in cell activation and cell cycle. Insertion of binding sites for the heterodimeric $\beta$-catenin/Tcf transcription factor into the parvoviral P4 promoter, resulted in wild-type replication kinetics in colon cells with activated wnt-signalling pathways, while burst size was reduced at least 1000 -fold in cell lines with inactive wntsignalling pathways. ${ }^{103}$

\section{Ways to enhance viral antitumor activity}

\section{Enhancement of viral intrinsic antitumor potency}

Although both many naturally occurring and engineered oncotropic viruses have been demonstrated to display specific oncolytic activity, there are few examples of complete tumor eradication. Therefore, attempts have been made to enhance the cytolytic effect of replication competent viruses (see Table 4).

Expression of cytotoxicity enhancing proteins. Several classes of cytotoxic proteins are under evaluation for improvement of the intrinsic potency of oncolytic viruses to kill cells. One such protein is the nuclear membrane glycoprotein E3-11.6kd, termed adenovirus death protein (ADP), which mediates efficient cell lysis and release of progeny virus from cells. ${ }^{104}$ However, ADP is deleted in the majority of oncolytic adenoviruses constructed to date. Adenovirus mutant CV787, containing a wild-type E3 region, showed enhanced target cell killing, relative to mutant adenovirus CV739 deleted for the E3 gene both in vitro and in vivo. ${ }^{81}$ Currently, CV787 is being evaluated in phase I and II clinical trials. Furthermore, Doronin et al ${ }^{105}$ reintroduced the ADP gene back into the genome of E3deleted, E1A-mutated replication competent viruses and 
demonstrated that it was expressed at higher levels than in natural infection, and that these viruses were more efficient in cell lysis and in causing tumor regression than their E3-deleted counterparts. Alteration of expression of other adenoviral proteins can also improve viral cytotoxic potency. For example, an adenovirus deleted for the E1B$19 \mathrm{kd}$ protein, which is a potent inhibitor of apoptosis, displayed more efficient cell killing of several tumor cell lines by apoptosis than a wild-type virus. ${ }^{107,108}$ Furthermore, overexpression of viral protein E4orf4, which is known to induce apoptosis in infected cells independently of p53, might also enhance adenovirus mediated cell killing. ${ }^{106}$ Expression of proteins that induce apoptosis have also been demonstrated to be beneficial to the intrinsic antitumor effect of autonomous parvovirus. A recombinant $\mathrm{H} 1$ parvovirus vector producing the apoptin protein (a tumor cell-specific, p53-independent, Bcl-2insensitive apoptotic effector) exhibited pronounced increased cytotoxic tumor cell-specific potency compared to the wild-type $\mathrm{H} 1$ virus. $^{36}$

It has recently been shown that expression of the fusogenic membrane glycoproteins (FMGs) of measles virus and gibbon ape leukemia virus in oncolytic viruses led to cell killing by fusing them into large multinucleated syncytia. Treatment of U87 glioma xenografts in nude mice with adenoviruses, harboring $\mathrm{F}$ and $\mathrm{H}$ FMGs of measles virus, led to a significantly higher antitumor effect compared to a control adenovirus. ${ }^{109}$ Similarly, an oncolytic HSV-1, in which genes of FMGs of gibbon ape leukemia virus were incorporated, showed a distinctive syncytial phenotype, leading to both increased cell killing ability in vitro and far better antitumor effects in vivo, relative to a nonfusogenic $\mathrm{HSV}-1 .{ }^{110}$ In vivo oncolytic potency of fusogenic HSV-1 was further enhanced when at the same time chemotherapeutic prodrug ganciclovir was administered. ${ }^{111}$

Eliciting an antitumor immune response. Although most research concerning oncolytic virotherapy focuses on enhancement of direct virus-mediated tumor cell killing, there are also studies that evaluate the use of oncolytic viruses as tools to elicit primarily an antitumor immune response. One such approach uses human tumor cells infected with an oncolytic virus (so-called oncolysates) in order to enhance the antigenicity of the tumor tissue and, as a consequence, evoke a systemic immune response against tumor-specific antigens. ${ }^{112}$ In recent phase III clinical trials of patients with stage III melanoma in a surgical adjuvant setting, administration of an vaccinia melanoma oncolysate, did not result in statistically significant improvement in disease-free interval or overall survival in all patients, but did confer a survival advantage in certain subsets of patients. ${ }^{113}$ In addition to vaccinia virus, NDV oncolysates have also been evaluated for eliciting melanoma-specific immune responses. Batliwalla et al ${ }^{114}$ performed a 15 -year followup study of patients with stage III malignant melanoma treated with an NDV oncolysate as part of clinical phase II trail study, that revealed an overall 15-year survival of $55 \%$. On the other hand, application of VSV in an oncolysate as a treatment for melanoma was not effective. $^{115}$

Furthermore, oncolytic viruses have been constructed that encode tumor-specific antigens in order to elicit an antitumoral immune response directly. Vaccinia viruses have been engineered that encode PSA or CEA, to generate an immune response against prostate cancer and several CEA expressing tumor types, respectively. A phase I trial showed that a PSA-encoding vaccinia virus was safe and, in combination with an immunostimulatory adjunct, it elicited PSA-specific T-cell responses and was able to inhibit tumor growth in several prostate cancer patients. ${ }^{116}$ In another phase I clinical trial of 18 patients with advanced tumors expressing (CEA), it was demonstrated that vaccination with vaccinia virus expressing CEA, induced $\mathrm{T}$-cell responses and antibody production directed against CEA, when treatment was followed by administration of CEA gene harboring avipox virus. Further increases in CEA-specific T-cell precursors were seen when local granulocyte-macrophage colony-stimulating factor (GM-CSF) and low-dose interleukin (IL)-2 were given with subsequent vaccinations. ${ }^{117}$

Direct transfer of cytokine genes to tumor cells has emerged as a third immunotherapeutic tool in oncolytic virotherapy to increase its antitumor efficacy. The rationale behind this approach is that expression of cytokine genes in tumor cells, delivered by oncotropic viruses, will stimulate inflammatory and immune responses against these cells, thereby enhancing the antitumor effects of oncolytic viruses. Zhang et $\mathrm{al}^{118}$ developed a replication competent adenoviral vector, in which the human interferon consensus gene was inserted, and showed that treatment of human breast cancer xenografts with this virus was associated with stronger tumor regression relative to the wild-type virus. Moreover, several oncolytic HSV-1s have been constructed that encode immunostimulatory agents. In several mouse models, it was shown that treatment with HSV-1 into which either IL-4 $4^{119}$ or IL-12 $2^{120,121}$ was incorporated, resulted in a significantly prolonged survival and stronger reduction in tumor volume compared to wild-type virus. Importantly, treatment was generally accompanied by accumulation of inflammatory cells, like $\mathrm{CD}^{+}$and $\mathrm{CD}^{+}$T-cells, suggesting that the increased therapeutic effect was caused by the induction of an antitumor immune response. Indeed, upon subsequent rechallenge with tumor cells, only $43 \%$ of the mice treated with HSV1-expressing IL-12 developed tumors compared to $86 \%$ of the mice treated with an analogous noncytokine-carrying HSV-1. ${ }^{121}$ Furthermore, in a phase I clinical trial with patients with surgically incurable subcutaneous melanoma, i.t. injections of a vaccinia virus carrying the gene for GM-CSF resulted in leukocytes infiltrates at the inoculated sites and five out of seven patients had complete or partial responses. ${ }^{122}$ On the other hand, treatment of patients bearing treatment-resistant malignant mesothelioma with vaccinia virus-IL-2 induced only a T-cell infiltrate in $50 \%$ of the tumor biopsies and no tumor regression was observed. ${ }^{123}$ The use of viruses with intrinsic oncotropic properties, like autonomous 
parvovirus, have also been evaluated as vectors to efficiently express therapeutic cytokines in human tumor cells. An autonomous parvovirus, H1, expressing IL-2 displayed better oncolytic properties than wild-type virus, as the formation of tumors from HeLa xenografts was reduced by $90 \%$ compared with wild-type or mockinfected cells probably due to infiltration of natural killer cells into tumor tissue. ${ }^{37}$

Altogether these studies demonstrate that expression of cytotoxicity-enhancing proteins and/or elicitation of an antitumor immune response are generally beneficial the antineoplastic effect of oncolytic viruses, and provide support for the use of these strategies in a therapeutic setting.

\section{Oncolytic virotherapy in a multimodal antitumor approach}

On the other hand, to increase the antitumor effect of oncolytic virotherapy, a multimodal cancer therapy is under evaluation utilizing oncolytic viruses in combination with chemotherapy, radiotherapy, or suicide gene therapy (Table 5). The rationale for this combination strategy is that combining therapies may have greater antitumor effects than either of these therapies alone. Second, the therapies have different safety profiles and may therefore without increased adverse events result in enhanced efficacy. Third, no overlapping resistance between oncolytic viruses and the other therapies is expected. And finally, it may be possible to lower treatment doses, thereby decreasing possible unwanted toxicity and still achieve greater efficacy than with single therapies.

Oncolytic viruses combined with chemotherapy. The antitumor activity of several oncolytic viruses in combination with chemotherapeutic drugs has been examined. Combined treatment of engineered adenoviruses CV787 and $\mathrm{CV} 890$, both targeted to $\mathrm{PSA}^{+}$prostate cells, with doxorubicin $^{124}$ (a topoisomerase II inhibitor that blocks DNA synthesis) or paclitaxel and docetaxel (taxane antimicrotubule agents) ${ }^{125}$ resulted in synergistic cytotoxic effects both in vitro and in vivo. Similarly, the antitumor effects of ONYX-015 in combination with chemotherapeutic drugs 5-fluorouracil (a pyrimidine antagonist that inhibits DNA synthesis), ${ }^{126}$ cisplatin (causing intrastrand DNA crosslinks that block DNA replication), $^{127}$ doxorubicin or paclitaxel ${ }^{128,129}$ were strongly enhanced or synergitic in several human tumor models (see Table 5). Combination therapy of ONYX-015 and chemotherapeutic drugs in clinical trials demonstrated the safeness of this treatment modality. ${ }^{55,56,130,131}$ However, in only one clinical trial significant higher tumor regression rates were evidenced compared to either monotherapy alone ${ }^{130}$ (see Table 6). Furthermore, some mouse model studies have reported strongly enhanced oncolytic efficiency of engineered HSV-1 vector G207 when applied in combination with cisplatin ${ }^{132}$ and vincristine. ${ }^{133}$ These studies show that the therapeutic effect of oncolytic viruses combined with chemotherapy is enhanced compared to the effect of either therapy alone and this dual mode of therapy can even exert synergistic effects in some instances. Importantly, chemotherapy did not inhibit the cytotoxic properties of the oncolytic viruses and, in some cases, lower treatment doses were sufficient to still exert increased antitumor effects compared to treatment with either therapy alone.

Oncolytic viruses combined with radiotherapy. The additive tumor-killing effects of several adenoviral vectors in combination with radiotherapy have been evaluated. Rogulski et $\mathrm{al}^{42}$ demonstrated that ONYX-015 viral therapy when combined with radiotherapy improved tumor control beyond that of either monotherapy. The therapeutic effect of another adenoviral vector, Ad5$\Delta 24 \mathrm{RGD}$, which contains an E1A mutation and an RGD-motif insertion in its fiber, resulting in retargeting to $\alpha_{\mathrm{v}}$ integrins expressing cells with pRb-pathway defects, in combination with radiotherapy was strongly enhanced in glioma cells both in vitro and in vivo. Furthermore, the cytotoxic effects of CV706, a prostate cell-specific adenovirus variant, toward the human prostate cancer cell line LNCaP was demonstrated to be synergistically enhanced when used in combination with radiation with no reduction in specificity. ${ }^{134}$ Moreover, the safeness of CV706 was confirmed in a phase I dose escalation study with patients with locally recurrent prostate cancer. ${ }^{80}$ Enhanced therapeutic effects were also observed when treatment of an HSV-1 mutant NV1020, lacking both copies of the $\gamma 34.5$ gene, was combined with ionizing radiation both in human U-87 malignant glioma ${ }^{135,136}$ and Hep3B hepatoma ${ }^{137}$ xenografts-bearing mice. On the other hand, combination therapy of low-dose radiation and infection with another replication-selective HSV mutant, G207, did exhibit increased antitumor effects against cervical tumors in vitro and in vivo ${ }^{138}$ but not in a prostate tumor mouse model. ${ }^{139}$

Altogether, these preclinical studies have shown us the beneficial effects of radiotherapy to oncolytic virotherapy. Several findings from these studies warrant further investigation. First, radiation did not impair viral replication, and, in several cases it even increased viral replication titers. ${ }^{135,137}$ Thus, this indicates that, unlike human genomes, viral genomes suffer relatively little damage by ionizing radiation, enabling them to replicate still with similar or even enhanced efficiency. Second, these studies have demonstrated that toxicity was not significantly increased in dual treatment regimens, compared to single therapies. Lastly, combination therapy of irradiation with nearly all tested oncolytic viruses led to an enhanced and sometimes even synergistic antitumor effect, relative to monotherapies. Although these preclinical studies are quite promising, clinical trials will have to be initiated to determine whether this mode of therapy is safe and can be used as a more efficient antitumor approach in patients as well.

Oncolytic viruses combined with suicide gene therapy. A third dual therapy approach that has been examined for enhanced antitumor efficacy of oncolytic viruses is the 
Table 5 Oncolytic virotherapy in combination with standard therapies in preclinical studies

\begin{tabular}{|c|c|c|c|c|c|}
\hline Parental strain & Agent & Chemotherapeutic drug & Effect & Tumor type & References \\
\hline \multicolumn{6}{|l|}{$\begin{array}{l}\text { Chemotherapy } \\
\text { treatment }\end{array}$} \\
\hline \multirow[t]{9}{*}{ Adenovirus } & CV890 & Doxorubicin & Synergistic & Liver cancer & 124 \\
\hline & CV787 & Paclitaxel & Synergistic & Prostate cancer & 125 \\
\hline & & Docetaxel & Synergistic & Prostate cancer & 125 \\
\hline & ONYX-015 & Doxorubicin & Synergistic & Thyroid cancer & 128 \\
\hline & & Paclitaxel & Synergistic & Thyroid cancer & 128 \\
\hline & & 5-Fluorouracil & Enhanced & HNSCC, colon cancer & 126 \\
\hline & & Cisplatin & Enhanced & HNSCC & 126 \\
\hline & & Cisplatin+paclitaxel & Synergistic & NSCLC & 129 \\
\hline & & Cisplatin+5-fluorouracil & Enhanced & HNSCC, ovarian cancer & 127 \\
\hline \multirow[t]{2}{*}{ HSV-1 } & G207 & Vincristine & Enhanced & Rhabdomyosarcoma & 133 \\
\hline & & Cisplatin & Synergistic & HNSCC & 132 \\
\hline \multicolumn{6}{|l|}{$\begin{array}{l}\text { Radiotherapy } \\
\text { treatment }\end{array}$} \\
\hline \multirow[t]{3}{*}{ Adenovirus } & ONYX-015 & & Additive & Colon cancer & 42 \\
\hline & Ad5- $\Delta 24 R G D$ & & Enhanced & Glioma & 164 \\
\hline & CV706 & & Synergistic & Prostate cancer & 134 \\
\hline \multirow[t]{3}{*}{ HSV-1 } & NV1020 & & Synergistic & Glioma & 135,136 \\
\hline & G207 & & Enhanced & Cervical cancer & 138 \\
\hline & & & No effect & Prostate cancer & 139 \\
\hline \multicolumn{6}{|l|}{$\begin{array}{l}\text { Suicide gene } \\
\text { therapy treatment }\end{array}$} \\
\hline \multirow[t]{7}{*}{ Adenovirus } & Ad-TK & Thymidine kinase & Enhanced & Glioma & 140 \\
\hline & & & Enhanced & Colon cancer & 141 \\
\hline & & & No effect & Colon cancer & 143 \\
\hline & & & No effect & Intraperitoneal tumours & 144 \\
\hline & & & No effect & HNSCC & 142 \\
\hline & Ad5-CD/TKrep & Cytosine deaminase/thymidine & Enhanced & Prostate cancer, glioma & 148 \\
\hline & & kinase fusion & Enhanced & Cervical cancer & 149 \\
\hline Vaccinia virus & VVCD & Cytosine deaminase & Enhanced & Colon adenocarcinoma & 165 \\
\hline \multirow[t]{2}{*}{ HSV-1 } & rRp450 & Cytochrome $P 450$ oxidase & Enhanced & Hepatocellular carcirnoma & 152,153 \\
\hline & & & Enhanced & Glioma & 154 \\
\hline VSV & VSV-C:U & Cytosine deaminase & Enhanced & Mammary carcinoma & 147 \\
\hline \multicolumn{6}{|c|}{ Suicide gene therapy+radiotherapy treatment } \\
\hline \multirow[t]{2}{*}{ Adenovirus } & Ad5-CD/TKrep & Cytosine deaminase/thymidine & Enhanced & Prostate, glioma & 148 \\
\hline & & kinase fusion & Enhanced & Cervical carcinoma & 149 \\
\hline $\begin{array}{l}\text { Adeno-associated } \\
\text { virus }\end{array}$ & AAVtk & Thymidine kinase & Enhanced & Laryngeal cancer & 156 \\
\hline
\end{tabular}

HSV-1, herpes simplex virus-1; VSV, vesicular stomatitis virus; HNSCC, head and neck squamous cell carcinoma; HSCLC, human small-cell lung carcinoma.

combination of oncolytic viruses with so-called suicide gene therapy. This strategy uses replication conditional viruses as gene transfer vehicles to specifically deliver 'suicide' genes to tumor cells. These suicide genes encode enzymes that convert an exogenously administered noncytotoxic prodrug into a noxious drug. By this mechanism, ideally, only tumor cells are killed due to disruption of DNA replication by the converted drug, while nontransfected cells remain unharmed. Thus, with this approach, systemic toxicity commonly associated with conventional chemotherapy is minimized. Of the many enzyme genes that have been studied for more efficient tumor cell killing by replication defective viruses, three are currently being evaluated in the context of replication competent viruses.

First, the most extensively studied prodrug-suicide gene combination is composed of the antiviral prodrug ganciclovir (GCV) and the HSV thymidine kinase gene (HSV-tk). The viral tk enzyme monophosphorylates GCV, which is then converted by cellular kinases to GCV triphosphate, an inhibitor of viral and cellular DNA synthesis. In addition, activated GCV can diffuse to neighboring, uninfected cells through gap junctions leading to additional cell killing above the direct cytotoxic effects of oncolytic viruses (Fig 3). Introduction of the HSV-t $k$ gene into oncolytic adenoviruses led to enhanced 
Table 6 Examples of oncolytic viruses in clinical trials

\begin{tabular}{|c|c|c|c|c|c|c|c|}
\hline Parental strain & Agent & Genetic alteration & Cancer targeted & $\begin{array}{l}\text { Combined with } \\
\text { other therapy }\end{array}$ & Phase & Reference & Therapeutic effect \\
\hline \multirow{11}{*}{$\begin{array}{l}\text { Adenovirus } 2 / 5 \\
\text { chimera }\end{array}$} & \multirow[t]{9}{*}{ ONYX-015 } & \multirow[t]{9}{*}{ E1B-55kd deletion } & \multirow[t]{3}{*}{ SCCHN } & No & II & 49 & $14 \%$ pr to $\mathrm{cr}, 41 \% \mathrm{sd}, 45 \% \mathrm{pd}$ \\
\hline & & & & No & I & 51 & No objective responses \\
\hline & & & & Chemotherapy & II & 130 & $27 \% \mathrm{cr}, 36 \% \mathrm{pr}, 37 \%$ sd \\
\hline & & & Ovarian cancer & No & I & 53 & No objective responses \\
\hline & & & $\begin{array}{l}\text { Primary and } \\
\text { secondary liver } \\
\text { tumors }\end{array}$ & No & $\mathrm{I} / \mathrm{II}$ & 54 & No objective responses \\
\hline & & & & Chemotherapy & II & 56 & $26 \% \mathrm{pr}, 33 \% \mathrm{sd}, 41 \% \mathrm{pd}$ \\
\hline & & & Pancreatic cancer & & I & 52 & No objective responses \\
\hline & & & Colorectal cancer & Chemotherapy & $\mathrm{I} / \mathrm{II}$ & 131 & $19 \%$ pr, $29 \%$ sd, $52 \%$ pd \\
\hline & & & & No & II & & $22 \% \mathrm{sd}, 78 \%$ pd \\
\hline & \multirow[t]{2}{*}{ Ad5-CD/TKrep } & \multirow{2}{*}{$\begin{array}{l}\text { E1B-55kd deletion; Insertion of } \\
\text { HSV-tk/CD fusion gene }\end{array}$} & Prostate cancer & $\begin{array}{l}\text { Suicide gene } \\
\text { therapy }\end{array}$ & I & 150 & $25 \%$ PSA decline in $63 \%$ of patients \\
\hline & & & & $\begin{array}{l}\text { Suicide gene } \\
\text { therapy+ } \\
\text { Radiotherapy }\end{array}$ & I & 155 & Significant PSA decline in all patients \\
\hline \multirow[t]{2}{*}{$\begin{array}{l}\text { Adenovirus } \\
\text { (serotype 5) }\end{array}$} & CV706 & $\begin{array}{l}\text { Regulation of E1A under PSA } \\
\text { promoter; E3 deletion }\end{array}$ & $\begin{array}{l}\text { Prostate cancer } \\
\text { (organ confined) }\end{array}$ & Radiotherapy & I & 80 & Significant PSA decline in all patients \\
\hline & CV787 & $\begin{array}{l}\text { Regulation of E1A under rat } \\
\text { probasin promoter and E1B } \\
\text { under PSA promoter; wild-type } \\
\text { E3 }\end{array}$ & $\begin{array}{l}\text { Prostate cancer } \\
\text { (organ confined and } \\
\text { metastatic) }\end{array}$ & No & I & Underway & - \\
\hline \multirow[t]{2}{*}{$\begin{array}{l}\text { Herpes simplex } \\
\text { virus-1 }\end{array}$} & G207 & $\begin{array}{l}\text { Deletion of both ã34.5 genes; } \\
\text { ribonucleotide reductase } \\
\text { disruption }\end{array}$ & Malignant glioma & No & $I-I I$ & 71 & $\begin{array}{l}\text { No replication data available, but } \\
\text { probably responses in some patients }\end{array}$ \\
\hline & NV1020 & $\begin{array}{l}\text { Deletion of one } \gamma 34.5 \text { gene; } \\
\text { deletion in tk gene; insertion of } \\
\text { exogenous copy of tk gene }\end{array}$ & $\begin{array}{l}\text { Colorectal } \\
\text { carcinoma liver } \\
\text { metastases }\end{array}$ & No & I & Underway & - \\
\hline \multirow[t]{4}{*}{ Vaccinia virus } & Vaccinia-oncolysate & None & Melanoma & No & III & 113 & \multirow{4}{*}{$\begin{array}{l}\text { Survival advantage in subset of } \\
\text { patients } \\
14 \% \mathrm{cr}, 57 \% \text { pr to } \mathrm{mr}, 29 \% \text { pd, tumor- } \\
\text { specific T cells } \\
\text { CEA-specific T cells and antibodies }\end{array}$} \\
\hline & Vaccinia-GM-CSF & $\begin{array}{l}\text { Insertion of GM-CSF gene into } \\
\text { tk gene }\end{array}$ & Melanoma & No & I & 122 & \\
\hline & Vaccinia-CEA & Insertion of CEA gene & $\begin{array}{l}\text { CEA expressing } \\
\text { tumors }\end{array}$ & No & I & 117 & \\
\hline & Vaccinia-PSA & Insertion of PSA gene & Prostate cancer & No & I & $\begin{array}{l}116 \\
166\end{array}$ & \\
\hline \multirow{3}{*}{$\begin{array}{l}\text { Newcastle disease } \\
\text { virus }\end{array}$} & 73-T-oncolysate & Naturally attenuated & Melanoma & No & II & 114 & \multirow{3}{*}{$\begin{array}{l}\text { Overall } 15 \text {-year survival of } 55 \% \text {, } \\
\text { tumor-specific T cell response } \\
4-31 \text { months sd, tumour specific T } \\
\text { cell response } \\
5-9 \text { years survival rates }\end{array}$} \\
\hline & PV701 & Naturally attenuated & $\begin{array}{l}\text { Advanced solid } \\
\text { cancers }\end{array}$ & No & I & 28 & \\
\hline & MTH-68/H & Naturally attenuated & Glioblastoma & No & I & 167 & \\
\hline Reovirus & Reolysin & None & $\mathrm{SCCHN}$ & No & I & 168 & $?$ \\
\hline
\end{tabular}

SCCHN, squamous cell carcinoma of head and neck; tk, thymidine kinase; PSA, prostate-specific antigen; CD, cytosine deaminase; cr, complete response; pr, partial response; sd, stable disease; pd, progressive disease. 
antitumor effects when these viruses were administered in conjunction with GCV prodrug, compared to treatment with the virus alone. ${ }^{140,141}$ In contrast, other studies have shown that addition of GCV did not lead to an increase in antitumor effect of HSV-tk-carrying adenoviruses. ${ }^{142-144}$ This might be explained by the fact that GCV, like the other prodrugs used in these studies, interferes with DNA synthesis in general, thereby being able to attenuate viral replication as well. This could lead to impairment of the oncolytic effect, resulting in an antagonistic action.

Second, Escherichia coli cytosine deaminase gene (CD) has also been evaluated for enhancement of therapeutic efficacy of oncolytic viruses. The CD enzyme converts prodrug 5-fluorocytosine (5-FC) into 5-fluorouracil (5FU), which blocks DNA synthesis. In this context, a replicating vaccinia virus expressing the $\mathrm{CD}$ gene showed improved antitumor effects in vitro and in vivo, compared with virotherapy alone. The effect of the $\mathrm{CD} / 5$-FC suicide gene mechanism on the oncolytic potency of autonomous parvovirus $(\mathrm{H} 1)$ has also proven to be beneficial, particular in combination with IL-2. ${ }^{145}$ Similar results were obtained from studies of an $\mathrm{E}^{-} \mathrm{B}^{-}$adenovirus harboring a ZD55-CD gene ${ }^{146}$ and a recombinant VSV in which the $\mathrm{CD} /$ uracil phosphoribosyltransferase gene was inserted. ${ }^{147}$ Freytag et al ${ }^{148}$ went one step further by evaluating the concept of combining two suicide gene systems with oncolytic virotherapy. The resulting E1Badenoviral vector, termed Ad5-CD/TKrep, containing a fusion gene encoding both cytosine deaminase (CD) and HSV-tk, exhibited markedly enhanced tumor cell-specific cytopathic effects in combination with either 5-FC or GCV administration, with the greatest effect when the virus was administered in combination with both prodrugs. ${ }^{148,149}$ In addition, in a phase I study with recurrent prostate cancer patients Ad5-CD/TKrep treatment did not only appear to be safe, but also resulted in an objective decrease in PSA levels. ${ }^{150}$

A third suicide gene that has been studied in combination with oncolytic viruses is the CYP2B1 gene. It encodes the cytochrome $P 450$ oxidase responsible for converting prodrugs like CPA to its DNA synthesis inhibiting metabolite phosphoramide mustard, which also diffuses to neighboring cells to produce bystander killing. A replication competent HSV-1 mutant, designated rRp450, has been constructed containing the CYP2B1 gene within its ribonucleotide reductase locus ${ }^{151}$ (see Figure 3). rRp450-mediated oncolysis in the presence of CPA was significantly increased both in vitro and in vivo. ${ }^{152,153}$ In contrast, as the viral $t k$ gene is still intact, cytotoxicity was reduced in the presence of ganciclovir ${ }^{152,153}$ although others have found the opposite ${ }^{154}$ (a possible explanation for these contradicting data has been described above).

Since the prodrug-suicide gene systems described here all exhibit potential antiviral activity, it is clear that timing and dose of prodrug delivery will be critical in the outcome of how viral replication is affected and will ultimately determine the antitumor efficacy of the combined therapy. Evaluation of other suicide gene systems will be important in order to find a system that does not attenuate viral replication and primarily possesses anticancer properties.

Oncolytic viruses in conjunction with both suicide gene therapy and radiotherapy. Efforts have been made to further enhance the cytopathic potency of oncolytic viruses by combining oncolytic virotherapy with both suicide gene therapy and radiotherapy. It was found that a trimodal approach involving replication competent adenovirus, Ad5-CD/TKrep, containing both $\mathrm{CD} / 5-\mathrm{FC}$ and $\mathrm{tk} / \mathrm{GCV}$ suicide gene systems, double suicide gene prodrugs, and radiotherapy led to greater cytotoxic effects compared to other dual treatment combinations. ${ }^{148,149}$ Recently, in a phase I clinical trial in patients with prostate cancer, the safety and efficacy of this threepronged therapy was demonstrated, ${ }^{155}$ with significant declines in PSA levels in all treated patients. A recent study reported that the trimodal approach was also very effective in potentiating the antitumoral activity of adenoassociated virus vectors. ${ }^{156}$ Taken together, it is anticipated that Ad5-CD/TKrep and possibly other vectors as well, in combination with suicide gene and radiation therapy, will have greater potential of destroying tumor cells and improving the survival of cancer patients.

\section{Discussion}

\section{Limitations and potential hurdles to overcome}

Although the oncolytic potency of both unmodified and genetically engineered viruses has been demonstrated in preclinical studies, the use of oncolytic viruses in destroying tumors in clinical trials has in most cases not yet been very successful (an overview of the oncolytic viruses that are currently evaluated in clinical trials is given in Table 6). Several factors have been identified that might explain this little therapeutic effect of oncolytic virotherapy in cancer patients in current studies.

In the first place, immune responses are likely to play a critical role in the antitumor efficacy of the therapy. On the one hand, it has been demonstrated that in addition to direct cytotoxic effects of viruses, viral treatment can elicit an antitumor immune response, that is beneficial to the outcome of the therapy. ${ }^{157-159}$ This is why an important strategy to enhance the antitumor potency of oncolytic viruses is based on this phenomenon. On the other hand, however, there are several reports indicating that immune responses can also lead to impediment of the antitumor activity of virotherapy particularly during systemic treatment modalities. ${ }^{22,160}$ Interestingly, the presence of high neutralizing antibodies titers does not abrogate viral infection and replication following i.t. injection. ${ }^{50}$ Probably, the immune system antagonizes the effectiveness of oncolytic viruses administered systemically, through inactivation of the virus, whereas once the virus has reached the tumor or is injected directly into it, the immune system will not negatively affect viral treatment anymore and might in theory enhance tumor regression, as is illustrated by studies summarized in Table 4. 
Furthermore, efficient viral spread within a tumor has been recognized as one of the most important parameters for antitumor efficacy following i.t. or systemic treatment. However, viral spread in solid tumors in vivo is often limited. ${ }^{161}$ Possibly, ineffective viral spread might relate to the relative large sizes of the viruses (for example, 90 and $120 \mathrm{~nm}$ for adenovirus and HSV-1, respectively), mixture of the tumor cell mass with normal cells (up to half of the cells in some tumors) or low expression of receptors needed for viral infection. It will be important to further evaluate approaches that improve viral spread within a tumor.

Lastly, there are indications that some viruses, for example ONYX-015, demonstrate less cell killing potential in a clinical setting than was expected from preclinical studies. ${ }^{41,42}$ Another factor that could potentially limit efficient tumor cell killing by oncolytic viruses in cancer patients is the heterogeneity of tumor cell populations. As a result, it is likely that oncolytic viruses are able to kill some tumor cell populations more efficiently than others.

\section{Safety concerns}

Apart from the therapeutic potency, the feasibility of oncolytic virotherapy will also depend on its safety profile. In the first place, the pathology and toxicity profile of oncolytic viruses should be determined. Until today, the safety of a small selection of engineered oncotropic viruses has been demonstrated in clinical trials (e.g. HSV-1-and adenovirus-derived vectors). Second, it will be important to determine the tropism of a newly genetically engineered virus. For instance, narrowing the tropism of a virus would pose no serious risk. Conversely, it could be dangerous when the tropism of a virus is extended to other tissues. Third, it should be examined what the chances and consequences are of reversion to or recombination with wild-type strains. Lastly, the ability to be transmitted to other humans could also pose a threat. In general, insertion of prodrug-activating enzyme genes, like the HSV-tk gene, will provide a safety mechanism that shuts down viral replication should nonspecific pathology arise or transmission occur.

\section{Conclusions}

The idea of using viruses to destroy tumor cells is tantalizing for the simplicity of its principle, and for the perspectives it raises. Unfortunately, their effective application is not as straight forward as we would have hoped for. Although, preclinical studies are quite promising, data from clinical trials are far less convincing. Although the overall safety of viral treatment was demonstrated, in most cases no objective antitumor responses were evidenced. These clinical trials have pointed out that hurdles like immune responses, systemic distribution and intratumoral spread are major limitations of this mode of therapy. In addition, they have highlighted the weakness of extrapolating therapeutic efficacy observed in preclinical studies to cancer patients.
To overcome these hurdles, it will still be of great importance to further optimize existing strategies and evaluate new possibilities in order to optimize the antitumor efficacy of oncolytic virotherapy, by for example combining multiple tumor-targeting mechanisms (manipulation of viral attachment proteins, the use of tumor-specific promoters and/or viral gene deletions) within one virus. On the other hand, combination of these tumor selectivity improving strategies with several toxicity-enhancing genes, such as genes encoding cytotoxic proteins, prodrug-converting enzymes and cytokines, could further potentiate the oncolytic potential of a virus and enable better viral spread within a tumor. Especially, the ability to elicit an antitumor immune response will be of great importance, because it is likely to be critical to the long-term success of the treatment. However, it is unknown whether all these features can be combined in one virus while maintaining replicative viability. Moreover, it raises further safety concerns due to altered phenotypic characteristics. Therefore, possession of a 'fail-safe' mechanism to prevent unwanted viral spread would be essential. Lastly, the therapeutic success will, for a large part, be dependent on the pharmacokinetic characteristics of administered viral vectors in patients. It will therefore be very important to get a better insight in the factors, like antiviral immune responses, that affect the pharmacology of oncolytic viruses. In this respect, optimization of the route of viral administration and the use of viruses that exhibit low immunogenicity and do not elicit a strong antiviral immune response could contribute to a better delivery to tumors and thereby higher therapeutic efficacy.

Altogether, despite the fact that additional modification of oncolytic viruses might result in increased oncolytic potency, as has been demonstrated with several second generation viruses, it is still unlikely that oncolytic virotherapy as a monotherapy will be able to fully eradicate tumors in a clinical setting. Therefore, as both preclinical and clinical trials suggest, inclusion of oncolytic viruses into a multimodal cancer treatment approach composed of standard radio-, gene-, and chemotherapies, will have the greatest potential of destroying tumors and improving the survival of cancer patients. It can be anticipated that further evaluation of oncolytic viruses as therapeutic tools in this setting will contribute to the extension of our anticancer armamentarium in the future.

\section{References}

1. Everett H, McFadden G. Apoptosis: an innate immune response to virus infection. Trends Microbiol. 1999;7: 160-165.

2. Madigan MT, Martinko JM, Parker J. Brock Biology of Microorganisms. 9th edn. Upper Saddal River, NJ: Prentice-Hall, Inc.; 2000.

3. de Pace N. Sulla scomparsa di un enorme cancro vegetante del collo dell'utero senza cura chirugica. Ginecologia. 1912;9:82-89. 
4. Bluming AZ, Ziegler JL. Regression of Burkitt's lymphoma in association with measles infection. Lancet. 1971;2:105-106.

5. Taqi AM, Abdurrahman MB, Yakubu AM, Fleming AF. Regression of Hodgkin's disease after measles. Lancet. 1981;1:1112.

6. Huebner RJ, Rowe WP, Schatten WE, Smith RR, Thomas LB. Studies on the use of viruses in the treatment of carcinoma of the cervix. Cancer. 1956;9:1211-1218.

7. Southam CM. Present status of oncolytic virus studies. Trans NY Acad Sci. 1960;22:657-673.

8. Asada T. Treatment of human cancer with mumps virus. Cancer. 1974;34:1907-1928.

9. Okuno Y, Asada T, Yamanishi K, et al. Studies on the use of mumps virus for treatment of human cancer. Biken $J$. 1978;21:37-49.

10. Webb HE, Molomut N, Padnos M, Wetherley-Mein G. The treatment of 18 cases of malignant disease with an arenavirus. Clin Oncol. 1975;1:157-169.

11. Webb HE, Wetherley-Mein G, Smith CE, McMahon D. Leukaemia and neoplastic processes treated with Langat and Kyasanur Forest disease viruses: a clinical and laboratory study of 28 patients. BMJ. 1966;5482: 258-266.

12. Martuza RL, Malick A, Markert JM, Ruffner KL, Coen DM. Experimental therapy of human glioma by means of a genetically engineered virus mutant. Science. 1991;252: 854-856.

13. Hashiro G, Loh PC, Yau JT. The preferential cytotoxicity of reovirus for certain transformed cell lines. Arch Virol. 1977;54:307-315.

14. Coffey MC, Strong JE, Forsyth PA, Lee PW. Reovirus therapy of tumors with activated Ras pathway. Science. 1998;282:1332-1334.

15. Strong JE, Lee PW. The V-erbB oncogene confers enhanced cellular susceptibility to reovirus infection. J Virol. 1996;70:612-616.

16. Strong JE, Coffey MC, Tang D, Sabinin P, Lee PW. The molecular basis of viral oncolysis: usurpation of the Ras signaling pathway by reovirus. EMBO J. 1998;17: 3351-3362.

17. Kinzler KW, Vogelstein B. Lessons from hereditary colorectal cancer. Cell. 1996;87:159-170.

18. Norman KL, Coffey MC, Hirasawa K, et al. Reovirus oncolysis of human breast cancer. Hum Gene Ther. 2002;13:641-652.

19. Alain T, Hirasawa K, Pon KJ, et al. Reovirus therapy of lymphoid malignancies. Blood. 2002;100:4146-4153.

20. Hirasawa K, Nishikawa SG, Norman KL, Alain T, Kossakowska A, Lee PW. Oncolytic reovirus against ovarian and colon cancer. Cancer Res. 2002;62: 1696-1701.

21. Thirukkumaran CM, Luider JM, Stewart DA, et al. Reovirus oncolysis as a novel purging strategy for autologous stem cell transplantation. Blood. 2003; 102:377-387.

22. Hirasawa K, Nishikawa SG, Norman KL, et al. Systemic reovirus therapy of metastatic cancer in immune-competent mice. Cancer Res. 2003;63:348-353.

23. Flanagan AD, Love R, Tesar W. Propagation of Newcastle disease virus in Ehrlich ascites cells in vitro and in vivo. Proc Soc Exp Biol Med. 1955;90:82-86.

24. Lorence RM, Katubig BB, Reichard KW, et al. Complete regression of human fibrosarcoma xenografts after local Newcastle disease virus therapy. Cancer Res. 1994;54: $6017-6021$
25. Phuangsab A, Lorence RM, Reichard KW, Peeples ME, Walter RJ. Newcastle disease virus therapy of human tumor xenografts: antitumor effects of local or systemic administration. Cancer Lett. 2001;172:27-36.

26. Sinkovics JG, Horvath JC. Newcastle disease virus (NDV): brief history of its oncolytic strains. J Clin Virol. 2000;16: $1-15$.

27. Mullen JT, Tanabe KK. Viral oncolysis. Oncologist 2002;7:106-119.

28. Pecora AL, Rizvi N, Cohen GI, et al. Phase I trial of intravenous administration of PV701, an oncolytic virus, in patients with advanced solid cancers. $J$ Clin Oncol. 2002;20:2251-2266.

29. Stojdl DF, Lichty B, Knowles S, et al. Exploiting tumorspecific defects in the interferon pathway with a previously unknown oncolytic virus. Nat Med. 2000;6:821-825.

30. Stojdl DF, Lichty BD, ten Oever BR, et al. VSV strains with defects in their ability to shutdown innate immunity are potent systemic anti-cancer agents. Cancer Cell. 2003;4:263-275.

31. Shinozaki K, Ebert O, Kournioti C, Tai YS, Woo SL. Oncolysis of multifocal hepatocellular carcinoma in the rat liver by hepatic artery infusion of vesicular stomatitis virus. Mol Ther. 2004;9:368-376.

32. Rommelaere J, Cornelis JJ. Antineoplastic activity of parvoviruses. J Virol Methods. 1991;33:233-251.

33. Herrero YC, Cornelis JJ, Herold-Mende C, Rommelaere J, Schlehofer JR, Geletneky K. Parvovirus H-1 infection of human glioma cells leads to complete viral replication and efficient cell killing. Int $J$ Cancer. 2004;109:76-84.

34. Cornelis JJ, Spruyt N, Spegelaere P, et al. Sensitization of transformed rat fibroblasts to killing by parvovirus minute virus of mice correlates with an increase in viral gene expression. J Virol. 1988;62:3438-3444.

35. Moehler M, Blechacz B, Weiskopf $N$, et al. Effective infection, apoptotic cell killing and gene transfer of human hepatoma cells but not primary hepatocytes by parvovirus H1 and derived vectors. Cancer Gene Ther. 2001;8:158-167.

36. Olijslagers S, Dege AY, Dinsart C, et al. Potentiation of a recombinant oncolytic parvovirus by expression of apoptin. Cancer Gene Ther. 2001;8:958-965.

37. Haag A, Menten P, Van Damme J, Dinsart C, Rommelaere J, Cornelis JJ. Highly efficient transduction and expression of cytokine genes in human tumor cells by means of autonomous parvovirus vectors; generation of antitumor responses in recipient mice. Hum Gene Ther. 2000;11:597-609.

38. Ring CJ. Cytolytic viruses as potential anti-cancer agents $J$ Gen Virol. 2002;83(Part 3):491-502.

39. Galanis E, Vile R, Russell SJ. Delivery systems intended for in vivo gene therapy of cancer: targeting and replication competent viral vectors. Crit Rev Oncol Hematol. 2001;38:177-192.

40. Post DE, Khuri FR, Simons JW, Van Meir EG. Replicative oncolytic adenoviruses in multimodal cancer regimens. Hum Gene Ther. 2003;14:933-946.

41. Bischoff JR, Kirn DH, Williams A, et al. An adenovirus mutant that replicates selectively in p53-deficient human tumor cells. Science. 1996;274:373-376.

42. Rogulski KR, Freytag SO, Zhang $\mathrm{K}$, et al. In vivo antitumor activity of ONYX-015 is influenced by p53 status and is augmented by radiotherapy. Cancer Res. 2000;60:1193-1196.

43. Goodrum FD, Ornelles DA. p53 status does not determine outcome of E1B 55-kilodalton mutant adenovirus lytic infection. $J$ Virol. 1998;72:9479-9490. 
44. Rothmann T, Hengstermann A, Whitaker NJ, Scheffner M, zur HH. Replication of ONYX-015, a potential anticancer adenovirus, is independent of p53 status in tumor cells. J Virol. 1998;72:9470-9478.

45. Harada JN, Berk AJ. p53-Independent and -dependent requirements for E1B-55K in adenovirus type 5 replication. J Virol. 1999;73:5333-5344.

46. Ries SJ, Brandts CH, Chung AS, et al. Loss of p14ARF in tumor cells facilitates replication of the adenovirus mutant d11520 (ONYX-015). Nat Med. 2000;6:11281133.

47. Dobner T, Horikoshi N, Rubenwolf S, Shenk T. Blockage by adenovirus E4orf6 of transcriptional activation by the p53 tumor suppressor. Science. 1996;272:1470 1473.

48. Kirn D. Oncolytic virotherapy for cancer with the adenovirus d11520 (Onyx-015): results of phase I and II trials. Expert Opin Biol Ther. 2001;1:525-538.

49. Nemunaitis J, Khuri F, Ganly I, et al. Phase II trial of intratumoral administration of ONYX-015, a replicationselective adenovirus, in patients with refractory head and neck cancer. J Clin Oncol. 2001;19:289-298.

50. Nemunaitis J, Ganly I, Khuri F, et al. Selective replication and oncolysis in p53 mutant tumors with ONYX-015, an E1B-55kD gene-deleted adenovirus, in patients with advanced head and neck cancer: a phase II trial. Cancer Res. 2000;60:6359-6366.

51. Ganly I, Kirn D, Eckhardt G, et al. A phase I study of Onyx-015, an E1B attenuated adenovirus, administered intratumorally to patients with recurrent head and neck cancer. Clin Cancer Res. 2000;6:798-806.

52. Mulvihill S, Warren R, Venook A, et al. Safety and feasibility of injection with an E1B-55 kDa gene-deleted, replication-selective adenovirus (ONYX-015) into primary carcinomas of the pancreas: a phase I trial. Gene Therapy. 2001;8:308-315.

53. Vasey PA, Shulman LN, Campos S, et al. Phase I trial of intraperitoneal injection of the E1B-55-kd-gene-deleted adenovirus ONYX-015 (d11520) given on days 1 through 5 every 3 weeks in patients with recurrent/refractory epithelial ovarian cancer. J Clin Oncol. 2002;20:15621569.

54. Habib NA, Sarraf CE, Mitry RR, et al. E1B-deleted adenovirus (d11520) gene therapy for patients with primary and secondary liver tumors. Hum Gene Ther. 2001;12: 219-226.

55. Reid T, Galanis E, Abbruzzese $J$, et al. Intra-arterial administration of a replication-selective adenovirus (d11520) in patients with colorectal carcinoma metastatic to the liver: a phase I trial. Gene Therapy. 2001;8: $1618-1626$.

56. Reid T, Galanis E, Abbruzzese J, et al. Hepatic arterial infusion of a replication-selective oncolytic adenovirus (d11520): phase II viral, immunologic, and clinical endpoints. Cancer Res. 2002;62:6070-6079.

57. Nemunaitis J, Cunningham $\mathrm{C}$, Buchanan A, et al. Intravenous infusion of a replication-selective adenovirus (ONYX-015) in cancer patients: safety, feasibility and biological activity. Gene Therapy. 2001;8:746-759.

58. Hamid O, Varterasian ML, Wadler S, et al. Phase II trial of intravenous CI-1042 in patients with metastatic colorectal cancer. J Clin Oncol. 2003;21:1498-1504.

59. Heise C, Hermiston T, Johnson L, et al. An adenovirus E1A mutant that demonstrates potent and selective systemic anti-tumoral efficacy. Nat Med. 2000;6: $1134-1139$.
60. Fueyo J, Gomez-Manzano C, Alemany R, et al. A mutant oncolytic adenovirus targeting the $\mathrm{Rb}$ pathway produces anti-glioma effect in vivo. Oncogene. 2000;19:2-12.

61. Gomez-Manzano C, Balague C, Alemany R, et al. A novel E1A-E1B mutant adenovirus induces glioma regression in vivo. Oncogene. 2004;23:1821-1828.

62. Cascallo M, Capella G, Mazo A, Alemany R. Rasdependent oncolysis with an adenovirus VAI mutant. Cancer Res. 2003;63:5544-5550.

63. Jia WW, McDermott M, Goldie J, Cynader M, Tan J, Tufaro F. Selective destruction of gliomas in immunocompetent rats by thymidine kinase-defective herpes simplex virus type 1. J Natl Cancer Inst. 1994;86: 1209-1215.

64. Boviatsis EJ, Scharf JM, Chase M, et al. Antitumor activity and reporter gene transfer into rat brain neoplasms inoculated with herpes simplex virus vectors defective in thymidine kinase or ribonucleotide reductase. Gene Therapy. 1994;1:323-331.

65. Whitley RJ, Kern ER, Chatterjee S, Chou J, Roizman B. Replication, establishment of latency, and induced reactivation of herpes simplex virus gamma 134.5 deletion mutants in rodent models. J Clin Invest. 1993;91: 2837-2843.

66. Bolovan CA, Sawtell NM, Thompson RL. ICP34.5 mutants of herpes simplex virus type 1 strain 17 syn + are attenuated for neurovirulence in mice and for replication in confluent primary mouse embryo cell cultures. $J$ Virol. 1994;68:48-55.

67. Mineta T, Rabkin SD, Martuza RL. Treatment of malignant gliomas using ganciclovir-hypersensitive, ribonucleotide reductase-deficient herpes simplex viral mutant. Cancer Res. 1994;54:3963-3966.

68. Carroll NM, Chiocca EA, Takahashi K, Tanabe KK. Enhancement of gene therapy specificity for diffuse colon carcinoma liver metastases with recombinant herpes simplex virus. Ann Surg. 1996;224:323-329.

69. Mineta T, Rabkin SD, Yazaki T, Hunter WD, Martuza RL. Attenuated multi-mutated herpes simplex virus- 1 for the treatment of malignant gliomas. Nat Med. 1995;1: 938-943.

70. Varghese S, Rabkin SD. Oncolytic herpes simplex virus vectors for cancer virotherapy. Cancer Gene Ther. 2002;9:967-978.

71. Markert JM, Medlock MD, Rabkin SD, et al. Conditionally replicating herpes simplex virus mutant, G207 for the treatment of malignant glioma: results of a phase I trial. Gene Therapy. 2000;7:867-874.

72. Meignier B, Longnecker R, Roizman B. In vivo behavior of genetically engineered herpes simplex viruses R7017 and R7020: construction and evaluation in rodents. $J$ Infect Dis. 1988;158:602-614.

73. Cozzi PJ, Malhotra S, McAuliffe P, et al. Intravesical oncolytic viral therapy using attenuated, replicationcompetent herpes simplex viruses G207 and Nv1020 is effective in the treatment of bladder cancer in an orthotopic syngeneic model. FASEB J. 2001;15: 1306-1308.

74. Bennett JJ, Delman KA, Burt BM, et al. Comparison of safety, delivery, and efficacy of two oncolytic herpes viruses (G207 and NV1020) for peritoneal cancer. Cancer Gene Ther. 2002;9:935-945.

75. Puhlmann M, Brown CK, Gnant M, et al. Vaccinia as a vector for tumor-directed gene therapy: biodistribution of a thymidine kinase-deleted mutant. Cancer Gene Ther. 2000;7:66-73. 
76. McCart JA, Ward JM, Lee J, et al. Systemic cancer therapy with a tumor-selective vaccinia virus mutant lacking thymidine kinase and vaccinia growth factor genes. Cancer Res. 2001;61:8751-8757.

77. Gromeier M, Lachmann S, Rosenfeld MR, Gutin PH, Wimmer E. Intergeneric poliovirus recombinants for the treatment of malignant glioma. Proc Natl Acad Sci USA. 2000;97:6803-6808.

78. Muster T, Rajtarova J, Sachet $\mathbf{M}$, et al. Interferon resistance promotes oncolysis by influenza virus NS1deletion mutants. Int $J$ Cancer. 2004;110:15-21.

79. Rodriguez R, Schuur ER, Lim HY, Henderson GA, Simons JW, Henderson DR. Prostate attenuated replication competent adenovirus (ARCA) CN706: a selective cytotoxic for prostate-specific antigen-positive prostate cancer cells. Cancer Res. 1997;57:2559-2563.

80. Deweese TL, Vander Poel H, Li S, et al. A phase I trial of CV706, a replication-competent, PSA selective oncolytic adenovirus, for the treatment of locally recurrent prostate cancer following radiation therapy. Cancer Res. 2001;61:7464-7472.

81. Yu DC, Chen Y, Seng M, Dilley J, Henderson DR. The addition of adenovirus type 5 region E3 enables calydon virus 787 to eliminate distant prostate tumor xenografts. Cancer Res. 1999;59:4200-4203.

82. Matsubara S, Wada Y, Gardner TA, et al. A conditional replication-competent adenoviral vector, Ad-OC-E1a, to cotarget prostate cancer and bone stroma in an experimental model of androgen-independent prostate cancer bone metastasis. Cancer Res. 2001;61:6012-6019.

83. Benjamin R, Helman L, Meyers P, Reaman G. A phase I/ II dose escalation and activity study of intravenous injections of $\mathrm{OCaP} 1$ for subjects with refractory osteosarcoma metastatic to lung. Hum Gene Ther. 2001;12:15911593.

84. Hallenbeck PL, Chang YN, Hay C, et al. A novel tumorspecific replication-restricted adenoviral vector for gene therapy of hepatocellular carcinoma. Hum Gene Ther. 1999;10:1721-1733.

85. Takahashi M, Sato T, Sagawa T, et al. E1B-55K-deleted adenovirus expressing E1A-13S by AFP-enhancer/promoter is capable of highly specific replication in AFPproducing hepatocellular carcinoma and eradication of established tumor. Mol Ther. 2002;5(5 Part 1):627-634.

86. Kurihara T, Brough DE, Kovesdi I, Kufe DW. Selectivity of a replication-competent adenovirus for human breast carcinoma cells expressing the MUC1 antigen. $J$ Clin Invest. 2000;106:763-771.

87. Nettelbeck DM, Rivera AA, Balague C, Alemany R, Curiel DT. Novel oncolytic adenoviruses targeted to melanoma: specific viral replication and cytolysis by expression of E1A mutants from the tyrosinase enhancer/ promoter. Cancer Res. 2002;62:4663-4670.

88. Banerjee NS, Rivera AA, Wang M, et al. Analyses of melanoma-targeted oncolytic adenoviruses with tyrosinase enhancer/promoter-driven E1A, E4, or both in submerged cells and organotypic cultures. Mol Cancer Ther. 2004;3:437-449.

89. Barker SD, Dmitriev IP, Nettelbeck DM, et al. Combined transcriptional and transductional targeting improves the specificity and efficacy of adenoviral gene delivery to ovarian carcinoma. Gene Therapy. 2003;10:1198-1204.

90. Adachi Y, Reynolds PN, Yamamoto M, et al. A midkine promoter-based conditionally replicative adenovirus for treatment of pediatric solid tumors and bone marrow tumor purging. Cancer Res. 2001;61:7882-7888.
91. Fuerer C, Iggo R. Adenoviruses with Tcf binding sites in multiple early promoters show enhanced selectivity for tumor cells with constitutive activation of the wnt signalling pathway. Gene Therapy. 2002;9:270-281.

92. Brunori M, Malerba M, Kashiwazaki H, Iggo $R$ Replicating adenoviruses that target tumors with constitutive activation of the wnt signaling pathway. $J$ Virol. 2001;75:2857-2865.

93. Tsukuda K, Wiewrodt R, Molnar-Kimber K, Jovanovic VP, Amin KM. An E2F-responsive replication-selective adenovirus targeted to the defective cell cycle in cancer cells: potent antitumoral efficacy but no toxicity to normal cell. Cancer Res. 2002;62:3438-3447.

94. Wirth T, Zender L, Schulte B, et al. A telomerasedependent conditionally replicating adenovirus for selective treatment of cancer. Cancer Res. 2003;63:3181-3188.

95. Huang Q, Zhang X, Wang H, et al. A novel conditionally replicative adenovirus vector targeting telomerase-positive tumor cells. Clin Cancer Res. 2004;10:1439-1445.

96. Bauerschmitz GJ, Nettelbeck DM, Kanerva A, et al. The flt-1 promoter for transcriptional targeting of teratocarcinoma. Cancer Res. 2002;62:1271-1274.

97. Post DE, Van Meir EG. A novel hypoxia-inducible factor (HIF) activated oncolytic adenovirus for cancer therapy. Oncogene. 2003;22:2065-2072.

98. Doronin K, Kuppuswamy M, Toth K, et al. Tissuespecific, tumor-selective, replication-competent adenovirus vector for cancer gene therapy. J Virol. 2001;75:3314-3324.

99. Miyatake S, Iyer A, Martuza RL, Rabkin SD. Transcriptional targeting of herpes simplex virus for cell-specific replication. J Virol. 1997;71:5124-5132.

100. Miyatake SI, Tani S, Feigenbaum F, et al. Hepatomaspecific antitumor activity of an albumin enhancer/ promoter regulated herpes simplex virus in vivo. Gene Therapy. 1999;6:564-572.

101. Yamamura H, Hashio M, Noguchi M, et al. Identification of the transcriptional regulatory sequences of human calponin promoter and their use in targeting a conditionally replicating herpes vector to malignant human soft tissue and bone tumors. Cancer Res. 2001;61:3969-3977.

102. Kasuya H, Pawlik TM, Mullen JT, et al. Selectivity of an oncolytic herpes simplex virus for cells expressing the DF3 MUC1 antigen. Cancer Res. 2004;64:2561-2567.

103. Malerba M, Daeffler L, Rommelaere J, Iggo RD. Replicating parvoviruses that target colon cancer cells. J Virol. 2003;77:6683-6691.

104. Tollefson AE, Scaria A, Hermiston TW, Ryerse JS, Wold $\mathrm{LJ}$, Wold WS. The adenovirus death protein $(\mathrm{E} 3-11.6 \mathrm{~K})$ is required at very late stages of infection for efficient cell lysis and release of adenovirus from infected cells. $J$ Virol. 1996;70:2296-2306.

105. Doronin K, Toth K, Kuppuswamy M, Ward P, Tollefson AE, Wold WS. Tumor-specific, replication-competent adenovirus vectors overexpressing the adenovirus death protein. $J$ Virol. 2000;74:6147-6155.

106. Shtrichman R, Kleinberger T. Adenovirus type 5 E4 open reading frame 4 protein induces apoptosis in transformed cells. J Virol. 1998;72:2975-2982.

107. Sauthoff H, Heitner S, Rom WN, Hay JG. Deletion of the adenoviral E1b-19kD gene enhances tumor cell killing of a replicating adenoviral vector. Hum Gene Ther. 2000; 11:379-388

108. Liu TC, Hallden G, Wang Y, et al. An E1B-19 kDa gene deletion mutant adenovirus demonstrates tumor necrosis factor-enhanced cancer selectivity and enhanced oncolytic potency. Mol Ther. 2004;9:786-803. 
109. Galanis E, Bateman A, Johnson K, et al. Use of viral fusogenic membrane glycoproteins as novel therapeutic transgenes in gliomas. Hum Gene Ther. 2001;12: 811-821.

110. Nakamori M, Fu X, Meng F, et al. Effective therapy of metastatic ovarian cancer with an oncolytic herpes simplex virus incorporating two membrane fusion mechanisms. Clin Cancer Res. 2003;9:2727-2733.

111. Nawa A, Nozawa N, Goshima F, et al. Oncolytic viral therapy for human ovarian cancer using a novel replication-competent herpes simplex virus type I mutant in a mouse model. Gynecol Oncol. 2003;91:81-88.

112. Savage HE, Rossen RD, Hersh EM, Freedman RS, Bowen JM, Plager C. Antibody development to viral and allogeneic tumor cell-associated antigens in patients with malignant melanoma and ovarian carcinoma treated with lysates of virus-infected tumor cells. Cancer Res. 1986;46(4 Part 2):2127-2133.

113. Wallack MK, Sivanandham M, Balch CM, et al. Surgical adjuvant active specific immunotherapy for patients with stage III melanoma: the final analysis of data from a phase III, randomized, double-blind, multicenter vaccinia melanoma oncolysate trial. J Am Coll Surg. 1998;187:69-77.

114. Batliwalla FM, Bateman BA, Serrano D, et al. A 15-year follow-up of AJCC stage III malignant melanoma patients treated postsurgically with Newcastle disease virus (NDV) oncolysate and determination of alterations in the CD8T cell repertoire. Mol Med. 1998;4:783-794.

115. Livingston PO, Albino AP, Chung TJ, et al. Serological response of melanoma patients to vaccines prepared from VSV lysates of autologous and allogeneic cultured melanoma cells. Cancer. 1985;55:713-720.

116. Eder JP, Kantoff PW, Roper K, et al. A phase I trial of a recombinant vaccinia virus expressing prostate-specific antigen in advanced prostate cancer. Clin Cancer Res. 2000;6:1632-1638.

117. Marshall JL, Hoyer RJ, Toomey MA, et al. Phase I study in advanced cancer patients of a diversified prime-andboost vaccination protocol using recombinant vaccinia virus and recombinant nonreplicating avipox virus to elicit anti-carcinoembryonic antigen immune responses. $J$ Clin Oncol. 2000;18:3964-3973.

118. Zhang JF, Hu C, Geng Y, et al. Treatment of a human breast cancer xenograft with an adenovirus vector containing an interferon gene results in rapid regression due to viral oncolysis and gene therapy. Proc Natl Acad Sci USA. 1996;93:4513-4518.

119. Andreansky S, He B, van Cott $\mathrm{J}$, et al. Treatment of intracranial gliomas in immunocompetent mice using herpes simplex viruses that express murine interleukins. Gene Therapy. 1998;5:121-130.

120. Parker JN, Gillespie GY, Love CE, Randall S, Whitley RJ, Markert JM. Engineered herpes simplex virus expressing IL-12 in the treatment of experimental murine brain tumors. Proc Natl Acad Sci USA. 2000;97:2208-2213.

121. Wong RJ, Patel SG, Kim S, et al. Cytokine gene transfer enhances herpes oncolytic therapy in murine squamous cell carcinoma. Hum Gene Ther. 2001;12:253-265.

122. Mastrangelo MJ, Maguire Jr HC, Eisenlohr LC, et al. Intratumoral recombinant GM-CSF-encoding virus as gene therapy in patients with cutaneous melanoma. Cancer Gene Ther. 1999;6:409-422.

123. Mukherjee S, Haenel T, Himbeck R, et al. Replicationrestricted vaccinia as a cytokine gene therapy vector in cancer: persistent transgene expression despite antibody generation. Cancer Gene Ther. 2000;7:663-670.
124. Li Y, Yu DC, Chen Y, et al. A hepatocellular carcinomaspecific adenovirus variant, CV890, eliminates distant human liver tumors in combination with doxorubicin. Cancer Res. 2001;61:6428-6436.

125. Yu DC, Chen Y, Dilley J, et al. Antitumor synergy of CV787, a prostate cancer-specific adenovirus, and paclitaxel and docetaxel. Cancer Res. 2001;61:517-525.

126. Heise C, Sampson-Johannes A, Williams A, McCormick F, Von Hoff DD, Kirn DH. ONYX-015, an E1B geneattenuated adenovirus, causes tumor-specific cytolysis and antitumoral efficacy that can be augmented by standard chemotherapeutic agents. Nat Med. 1997;3:639-645.

127. Heise C, Lemmon M, Kirn D. Efficacy with a replicationselective adenovirus plus cisplatin-based chemotherapy: dependence on sequencing but not p53 functional status or route of administration. Clin Cancer Res. 2000;6: 4908-4914.

128. Portella G, Scala S, Vitagliano D, Vecchio G, Fusco A. ONYX-015, an E1B gene-defective adenovirus, induces cell death in human anaplastic thyroid carcinoma cell lines. $J$ Clin Endocrinol Metab. 2002;87:2525-2531.

129. You L, Yang CT, Jablons DM. ONYX-015 works synergistically with chemotherapy in lung cancer cell lines and primary cultures freshly made from lung cancer patients. Cancer Res. 2000;60:1009-1013.

130. Khuri FR, Nemunaitis J, Ganly I, et al. A controlled trial of intratumoral ONYX-015, a selectively-replicating adenovirus, in combination with cisplatin and 5-fluorouracil in patients with recurrent head and neck cancer. Nat Med. 2000;6:879-885.

131. Hecht JR, Bedford R, Abbruzzese JL, et al. A phase I/II trial of intratumoral endoscopic ultrasound injection of ONYX-015 with intravenous gemcitabine in unresectable pancreatic carcinoma. Clin Cancer Res. 2003;9: 555-561.

132. Chahlavi A, Todo T, Martuza RL, Rabkin SD. Replication-competent herpes simplex virus vector G207 and cisplatin combination therapy for head and neck squamous cell carcinoma. Neoplasia. 1999;1:162-169.

133. Cinatl Jr J, Cinatl J, Michaelis M, et al. Potent oncolytic activity of multimutated herpes simplex virus G207 in combination with vincristine against human rhabdomyosarcoma. Cancer Res. 2003;63:1508-1514.

134. Chen Y, DeWeese T, Dilley J, et al. CV706, a prostate cancer-specific adenovirus variant, in combination with radiotherapy produces synergistic antitumor efficacy without increasing toxicity. Cancer Res. 2001;61: 5453-5460.

135. Advani SJ, Sibley GS, Song PY, et al. Enhancement of replication of genetically engineered herpes simplex viruses by ionizing radiation: a new paradigm for destruction of therapeutically intractable tumors. Gene Therapy. 1998; 5:160-165.

136. Bradley JD, Kataoka Y, Advani S, et al. Ionizing radiation improves survival in mice bearing intracranial high-grade gliomas injected with genetically modified herpes simplex virus. Clin Cancer Res. 1999;5:1517-1522.

137. Chung SM, Advani SJ, Bradley JD, et al. The use of a genetically engineered herpes simplex virus (R7020) with ionizing radiation for experimental hepatoma. Gene Therapy. 2002;9:75-80.

138. Blank SV, Rubin SC, Coukos G, Amin KM, Albelda SM, Molnar-Kimber KL. Replication-selective herpes simplex virus type 1 mutant therapy of cervical cancer is enhanced by low-dose radiation. Hum Gene Ther. 2002;13:627639. 
139. Jorgensen TJ, Katz S, Wittmack EK, et al. Ionizing radiation does not alter the antitumor activity of herpes simplex virus vector G207 in subcutaneous tumor models of human and murine prostate cancer. Neoplasia. 2001;3:451-456.

140. Nanda D, Vogels R, Havenga M, Avezaat CJ, Bout A, Smitt PS. Treatment of malignant gliomas with a replicating adenoviral vector expressing herpes simplex virusthymidine kinase. Cancer Res. 2001;61:8743-8750.

141. Wildner O, Blaese RM, Morris JC. Therapy of colon cancer with oncolytic adenovirus is enhanced by the addition of herpes simplex virus-thymidine kinase. Cancer Res. 1999;59:410-413.

142. Morris JC, Wildner O. Therapy of head and neck squamous cell carcinoma with an oncolytic adenovirus expressing HSV-tk. Mol Ther. 2000;1:56-62.

143. Wildner O, Morris JC. Therapy of peritoneal carcinomatosis from colon cancer with oncolytic adenoviruses. $J$ Gene Med. 2000;2:353-360.

144. Lambright ES, Amin K, Wiewrodt R, et al. Inclusion of the herpes simplex thymidine kinase gene in a replicating adenovirus does not augment antitumor efficacy. Gene Therapy. 2001;8:946-953.

145. Hajri A, Wack S, Dinsart C, Cornelis JJ, Rommelaere J, Aprahamian M. Autonomous parvovirus H1-mediated combination suicide and cytokine gene therapy for pancreatic adenocarcinoma. Pancreatology. 2002;2: 217-361.

146. Zhang ZL, Zou WG, Luo CX, et al. An armed oncolytic adenovirus system, ZD55-gene, demonstrating potent antitumoral efficacy. Cell Res. 2003;13:481-489.

147. Porosnicu M, Mian A, Barber GN. The oncolytic effect of recombinant vesicular stomatitis virus is enhanced by expression of the fusion cytosine deaminase/uracil phosphoribosyltransferase suicide gene. Cancer Res. 2003;63: 8366-8376.

148. Freytag SO, Rogulski KR, Paielli DL, Gilbert JD, Kim JH. A novel three-pronged approach to kill cancer cells selectively: concomitant viral, double suicide gene, and radiotherapy. Hum Gene Ther. 1998;9:1323-1333.

149. Rogulski KR, Wing MS, Paielli DL, Gilbert JD, Kim JH, Freytag SO. Double suicide gene therapy augments the antitumor activity of a replication-competent lytic adenovirus through enhanced cytotoxicity and radiosensitization. Hum Gene Ther. 2000;11:67-76.

150. Freytag SO, Khil M, Stricker H, et al. Phase I study of replication-competent adenovirus-mediated double suicide gene therapy for the treatment of locally recurrent prostate cancer. Cancer Res. 2002;62:4968-4976.

151. Chase M, Chung RY, Chiocca EA. An oncolytic viral mutant that delivers the CYP2B1 transgene and augments cyclophosphamide chemotherapy. Nat Biotechnol. 1998;16: 444-448.

152. Pawlik TM, Nakamura H, Yoon SS, et al. Oncolysis of diffuse hepatocellular carcinoma by intravascular administration of a replication-competent, genetically engineered herpesvirus. Cancer Res. 2000;60:2790-2795.

153. Pawlik TM, Nakamura H, Mullen JT, et al. Prodrug bioactivation and oncolysis of diffuse liver metastases by a herpes simplex virus 1 mutant that expresses the CYP2B1 transgene. Cancer. 2002;95:1171-1181.
154. Aghi M, Chou TC, Suling K, Breakefield XO, Chiocca EA. Multimodal cancer treatment mediated by a replicating oncolytic virus that delivers the oxazaphosphorine/rat cytochrome P450 2B1 and ganciclovir/herpes simplex virus thymidine kinase gene therapies. Cancer Res. 1999; 59:3861-3865.

155. Freytag SO, Stricker H, Pegg J, et al. Phase I study of replication-competent adenovirus-mediated double-suicide gene therapy in combination with conventional-dose threedimensional conformal radiation therapy for the treatment of newly diagnosed, intermediate- to high-risk prostate cancer. Cancer Res. 2003;63:7497-7506.

156. Kanazawa T, Mizukami H, Okada T, et al. Suicide gene therapy using AAV-HSVtk/ganciclovir in combination with irradiation results in regression of human head and neck cancer xenografts in nude mice. Gene Therapy. 2003; 10:51-58.

157. Toda M, Rabkin SD, Kojima H, Martuza RL. Herpes simplex virus as an in situ cancer vaccine for the induction of specific anti-tumor immunity. Hum Gene Ther. 1999;10:385-393.

158. Todo T, Rabkin SD, Sundaresan P, et al. Systemic antitumor immunity in experimental brain tumor therapy using a multimutated, replication-competent herpes simplex virus. Hum Gene Ther. 1999;10:2741-2755.

159. Toda M, Iizuka Y, Kawase T, Uyemura K, Kawakami Y. Immuno-viral therapy of brain tumors by combination of viral therapy with cancer vaccination using a replicationconditional HSV. Cancer Gene Ther. 2002;9: $356-364$.

160. Ikeda K, Ichikawa T, Wakimoto H, et al. Oncolytic virus therapy of multiple tumors in the brain requires suppression of innate and elicited antiviral responses. Nat Med. 1999;5:881-887.

161. Heise CC, Williams A, Olesch J, Kirn DH. Efficacy of a replication-competent adenovirus (ONYX-015) following intratumoral injection: intratumoral spread and distribution effects. Cancer Gene Ther. 1999;6:499-504.

162. Sherr CJ. The Pezcoller lecture: cancer cell cycles revisited. Cancer Res. 2000;60:3689-3695.

163. Wong RJ, Chan MK, Yu Z, et al. Effective intravenous therapy of murine pulmonary metastases with an oncolytic herpes virus expressing interleukin 12. Clin Cancer Res. 2004;10(1 Part 1):251-259.

164. Lamfers ML, Grill J, Dirven CM, et al. Potential of the conditionally replicative adenovirus Ad5-Delta24RGD in the treatment of malignant gliomas and its enhanced effect with radiotherapy. Cancer Res. 2002;62:5736-5742.

165. McCart JA, Puhlmann M, Lee J, et al. Complex interactions between the replicating oncolytic effect and the enzyme/prodrug effect of vaccinia-mediated tumor regression. Gene Therapy. 2000;7:1217-1223.

166. Gulley J, Chen AP, Dahut W, et al. Phase I study of a vaccine using recombinant vaccinia virus expressing PSA (rV-PSA) in patients with metastatic androgen-independent prostate cancer. Prostate. 2002;53:109-117.

167. Csatary LK, Gosztonyi G, Szeberenyi J, et al. MTH-68/H oncolytic viral treatment in human high-grade gliomas. J Neurooncol. 2004;67:83-93.

168. Oncolytics Biotech releases REOLYSIN phase I clinical trial results. Expert Rev Anticancer Ther. 2002;2:139. 